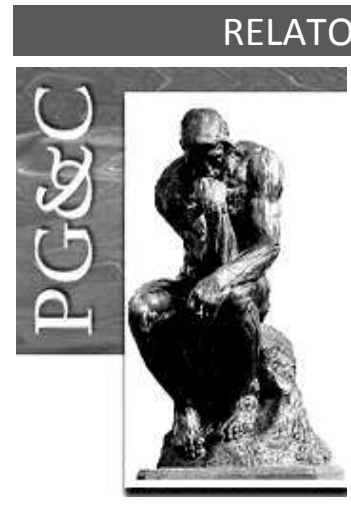

\title{
AVALIAÇÃO DA GESTÃO DAS EMPRESAS CONSTRUTORAS DE PEQUENO E MÉDIO PORTE DE CURITIBA QUANTO AO NÍVEL DE ADERÊNCIA ÀS PRÁTICAS DE GESTÃO DO CONHECIMENTO
}

\author{
Gizele Pires Staidel \\ Mestre em Engenharia Civil pela Universidade Tecnológica Federal do \\ Paraná, Brasil. Brasil. \\ E-mail: gi staidel@hotmail.com
}

Cesar Augusto Romano

Doutor em Engenharia de produção pela Universidade Federal de Santa Catarina, Brasil. Professor da Universidade Tecnológica Federal do Paraná, Brasil.

E-mail: romano.utfpr@gmail.com

\begin{abstract}
Resumo
Considerando-se a importância da indústria da construção para o país é importante conhecer as práticas de gestão do conhecimento que são atualmente utilizadas e como estas práticas podem ser melhoradas de forma a apoiar a melhoria da produtividade. $O$ presente trabalho tem como objetivo avaliar a gestão das empresas construtoras de pequeno e médio porte de Curitiba quanto ao nível de aderência às práticas de Gestão do Conhecimento, por meio da realização de um diagnóstico, conforme modelo proposto no Guia Europeu de Boas Práticas de Gestão do Conhecimento. Este guia estabelece cinco atividades do conhecimento, sendo elas: identificação, criação, armazenamento, compartilhamento e uso. A pesquisa é classificada como: quantitativa, aplicada, descritiva, e quanto ao procedimento de pesquisa, como survey. Obtém respostas de 32 empresas e 45 respondentes entre Direção e Colaboradores. São considerados como Colaboradores os profissionais das áreas de Qualidade ou Engenharia. Os resultados demonstram que há compatibilidade das respostas entre a Direção e Colaboradores, sendo estas aderentes ao tema. Comparando-se os resultados deste estudo com outros estudos que utilizaram a metodologia proposta por Bukowitz e Williams (2002), considerando-se apenas o processo tático, percebeu-se uma aderência, em média, 6,7\% maior obtida pelas empresas construtoras. Se considerada a média geral, incluindo o processo estratégico, a diferença foi ainda maior, com diferença de $9,3 \%$.
\end{abstract}

Palavras-chave: Gestão do Conhecimento. Construção Civil. Pequenas e médias empresas.

\section{EVALUATION OF THE MANAGEMENT LEVEL OF SMALL AND MEDIUMSIZED BUILDING COMPANIES OF CURITIBA ABOUT ADHERENCE LEVEL TO KNOWLEDGE MANAGEMENT PRACTICES}

\begin{abstract}
Considering the importance of the construction industry for the country, it is important to know the knowledge management practices that are currently used and how these practices can be improved in order to support the improvement of productivity. This work aims to evaluate the management of small and medium-sized construction companies in Curitiba regarding the level of adherence to Knowledge Management practices, by performing a diagnosis, according to the model proposed in the European Guide to Good Management Practices Knowledge. This guide defines five knowledge activities, namely: identification, creation, storage, sharing and use. This research was used as: quantitative, applied, descriptive and as the research procedure, as research. Responses from 32 companies and 45 participants including management and employees were included. They were considered as
\end{abstract}

Perspectivas em Gestão \& Conhecimento, João Pessoa, v. 10, n. 3, p. 47-74, set./dez. 2020. DOI: https://dx.doi.org/10.22478/ufpb.2236-417X.2020v10n3.54868

http://periodicos.ufpb.br/ojs2/index.php/pgc. ISSN: 2236-417X. Publicação sob Licença (cc) EY-Nc-ND 
collaborators or professionals in the Quality or Engineering areas. The results show that there is compatibility of responses between management and employees, who are adherent to the theme. Comparing the results of this study with other studies that used the methodology proposed by Bukowitz and Williams (2002), considering only the tactical process, perceived as an adherence, on average, $6.7 \%$ higher by the construction companies. If you consider a general average, including the strategic process, the difference was even greater, with a difference of $9.3 \%$.

Keywords: Knowledge Management; Construction; Small and Medium Business.

\section{INTRODUÇÃO}

A construção civil tem grande importância no cenário nacional quando considerados os dados do Produto Interno Bruto (PIB), impactando no desenvolvimento econômico do país.

Em 2014, um estudo de Análise da Produtividade do Setor de Construção Civil, pela FGV - Fundação Getúlio Vargas, atualizou uma pesquisa realizada em 2012. Este estudo analisou o período de 2007 e 2012 e demonstrou que a produtividade na Construção civil vem caindo ao longo do tempo, com um declínio médio de $0,4 \%$ ao ano sendo que o estudo mostra a produtividade diretamente relacionada com a qualificação da mão de obra.

Em outro estudo realizado pela FGV (2014) sobre os desafios da Construção Civil para 2020, a qualificação de pessoal foi o fator considerado mais importante para a competitividade e produtividade na construção civil, sendo as formas de capacitação mais utilizadas, as fornecidas e organizadas pela própria empresa, que representam $87 \%$ das iniciativas.

Quanto às estratégias de inovação, a pesquisa realizada pela FGV (2014) identificou como as estratégias mais utilizadas a pesquisa própria, desenvolvida internamente na empresa, com $74 \%$.

Em relação ao uso de tecnologia, os estudos indicam que o segmento tem consciência da importância das tecnologias voltadas à gestão e associadas à industrialização da produção.

Considerando-se a importância da indústria da construção para o país e o cenário acima apresentado, é de extrema importância conhecer as práticas de gestão do conhecimento que são atualmente utilizadas e como estas práticas podem ser melhoradas de forma a apoiar a melhoria da produtividade. Além disso, a aplicabilidade do estudo extrapola o segmento de construção civil, podendo ser aplicado em diversos outros segmentos.

A pesquisa foi realizada utilizando-se o modelo de diagnóstico de Gestão do Conhecimento (GC) proposto pelo Guia Europeu de Boas Práticas de Gestão do Conhecimento, visto que durante a análise bibliométrica de publicações por território, foi constatado que a maior parte das publicações sobre GC em pequenas e médias empresas são oriundas da Europa. Esta decisão foi corroborada pelo estudo de Trindade et.al (2016) que avaliaram algumas propostas para aplicação da gestão do conhecimento em organizações, sendo que constataram que as soluções de GC abordadas para pequenas e médias empresas não são tão numerosas quanto as soluções para as grandes empresas tanto no Brasil como em grande parte dos países e que o Guia Europeu de Boas Práticas em Gestão do Conhecimento apresenta um framework com foco específico na "gestão do conhecimento" para PMES.

O presente trabalho tem como objetivo avaliar a gestão das empresas construtoras de pequeno e médio porte de Curitiba quanto ao nível de aderência às práticas de Gestão do Conhecimento, por meio da realização de um diagnóstico, conforme modelo proposto no Guia Europeu de Boas Práticas de Gestão do Conhecimento.

O alcance do objetivo geral proposto, impõe a consecução dos seguintes objetivos específicos: Realizar um diagnóstico de GC nas empresas construtoras, de forma a obter informações a respeito das práticas atualmente utilizadas nas empresas; Identificar se há

Perspectivas em Gestão \& Conhecimento, João Pessoa, v. 10, n. 3, p. 47-74, set./dez. 2020. 
convergência entre a visão da Alta Direção e Colaboradores (Engenheiros/Qualidade) sobre a GC; e, comparar o resultado deste estudo com outros similares realizados por Bukowitz e Williams (2002), que afirmam que o nível de aderência de pequenas e médias empresas é de aproximadamente $55 \%$.

Uma vez atingidos os objetivos propostos, espera-se trazer uma contribuição para o setor produtivo, das atuais práticas de GC que são mais usualmente adotadas pelas empresas e quais práticas podem ser melhoradas de forma a contribuir para um melhor desempenho da empresa e geração de vantagem competitiva.

Foi delimitado como campo de pesquisa as empresas construtoras de obras residenciais, comerciais e industriais, que estejam classificadas como pequenas ou médias empresas, de acordo com critérios estabelecidos pelo Serviço Brasileiro de Apoio às Micro e Pequenas Empresas (SEBRAE) e que atuam em Curitiba - PR.

Foi estabelecida como base de dados as empresas constantes do Cadastro das Indústrias do Estado do Paraná do ano de 2017, onde estão relatadas 102 empresas de pequeno e médio porte, considerando-se que a delimitação se dá pelo número de funcionários que deve estar entre 20 e 499. Para garantir a confiabilidade de $90 \%$ com margem de erro de $10 \%$, foi definida como amostra de investigação 32 empresas construtoras.

Esta pesquisa foi classificada como: quantitativa, aplicada, descritiva, e quanto ao procedimento de pesquisa, como survey.

As etapas da pesquisa foram compostas de pesquisa bibliográfica, análise bibliométrica, elaboração do questionário de pesquisa, aplicação de questionário piloto, revisão do instrumento de pesquisa, definição da amostra, aplicação do questionário e análise de dados.

\section{REFERENCIAL TEÓRICO}

Leone (1999) já citava que as especificidades organizacionais das pequenas e médias empresas quanto à sua forma de gestão e de organização estão relacionadas à tendência de possuírem uma estrutura simples e menos formalizadas e à centralização da gestão na pessoa do proprietário. Quanto ao processo de tomada de decisão, ela normalmente é baseada na experiência, no julgamento ou na intuição do proprietário e marcada não somente pela sua racionalidade econômica, mas também por sua racionalidade política e familiar. O proprietário não dispõe de tempo e nem da habilidade necessária para adotar uma atitude mais analítica e estratégica, sendo muito mais um estrategista que corre riscos do que um gestor que procura minimizar os riscos. Neste tipo de empresa pode-se dizer que ocorre a personalização da pessoa na gestão da figura do seu dirigente.

Freitas e Krai (2010) afirmam que, para a adaptação às novas realidades, faz-se necessária uma adequação no processo de gestão dessas organizações, buscando a profissionalização da gestão familiar, passando pela avaliação da situação atual e pelo levantamento das necessidades de alteração. A empresa não deve apenas investir nos familiares atuantes na empresa, mas também nos colaboradores que fazem parte dela. É necessário capacitar o novo líder sucessor, dando-lhe suporte, para agregar valor à sua formação profissional e acadêmica e também para a gestão dos negócios da empresa familiar.

Segundo análise dos dados do Instituto Brasileiro de Geografia e Estatística (IBGE), pode-se afirmar que a indústria da Construção Civil é muito relevante no cenário nacional.

A participação da indústria da Construção Civil na população ocupada, em média, de 2000 a 2014 foi de 7,35\%. A média do período de 2010 a 2014 foi de $8,38 \%$, conforme dados do IBGE (IBGE, 2014). 
O PIB, no ano de 2015 , foi de $5,7 \%$, sendo que a média de 2000 a 2015 foi de $5,6 \%$. Os $5,7 \%$ representam 25,5\% do total do PIB da indústria nacional, que foi de 22,3\% em 2015 (IBGE, 2015).

A partir de 2011 até o presente momento, houve uma desaceleração expressiva do crescimento do setor da construção civil. Em função dessa situação, torna-se primordial a obtenção de ganhos de produtividade, bem como planejamento e gestão efetiva de processos, emprego de novas tecnologias e qualificação dos trabalhadores (CBIC, 2014).

Comparando-se o estudo realizado em 2014 com outro realizado em 2012, pela Fundação Getúlio Vargas (FGV), a pedido da Câmara Brasileira da Indústria da Construção (CBIC), o mesmo demonstrou que a produtividade no setor vem diminuindo (CBIC, 2014).

Conforme o estudo realizado, é possível afirmar que a falta de qualificação afeta diretamente os ganhos de produtividade, que poderiam resultar em aumento do rendimento real do trabalhador.

Conforme o Boletim de Tendências do SEBRAE, do período de setembrooutubro/2017, deve-se considerar que, como a indústria da construção possui ciclos de produção sazonais e está sujeita ao cenário econômico, a rotatividade da mão de obra pode dificultar a assimilação de boas práticas. Com a ampliação da terceirização, é importante manter treinamento contínuo da equipe para obter maior eficiência e respeito às normas do setor (SEBRAE, 2017).

Quanto ao estágio de desenvolvimento tecnológico do Brasil, os estudos da FGV (2014) indicam a percepção predominante de que o segmento Construção de Edifícios no Brasil encontra-se em estágio intermediário de desenvolvimento tecnológico, com viés de baixo desenvolvimento. Cerca de $80 \%$ dos entrevistados percebem estágio atrasado ou intermediário para o segmento.

A ideia do compartilhamento de informação, produtos, serviços e experiências, para KALIL e LOPES (2018), não é nova, mas reverberam nesse modelo econômico inovador conhecido como economia colaborativa ou compartilhada, pois as ferramentas tecnológicas que a sociedade atual possui amplificam essas atitudes.

Conforme citado por Terra (2003), os conceitos e práticas de GC podem ser aplicados, com bons resultados, à pequena e média empresa nacional. Para isso, faz-se necessária a adequação da linguagem e ferramentas e que práticas sejam adaptadas à realidade das PMEs, considerando as possibilidades, desafios e as condições financeiras das empresas.

Há um equívoco no entendimento de que a GC exige grandes investimentos em informática, pessoal dedicado e recursos para pagamento de consultores. Outro erro, é pensar que a GC só é aplicável às áreas de chão de fábrica, desenvolvimento de novos produtos ou áreas em contato com clientes. Apesar de ser necessária uma atenção especial, focada e sistemática, os conceitos e ferramentas de GC podem ser bastante úteis para as PMEs, podendo ter elevada importância na competitividade das empresas (TERRA, 2003).

Para Ezequiel, Yamaguchi e Watanabe (2019), na era do conhecimento quem possui capital intelectual e consegue gerenciá-lo compreende melhor e fazem as organizações alcancem âmbitos maiores no mercado, e não mais apenas o capital econômico.

Segundo o Guia Europeu (2004), uma abordagem de GC é especialmente importante para as PMEs devido ao fato de que o conhecimento neste tipo de empresa tende a ser tácito, informal e não registrado. O know-how nas PMEs pode não ser valorizado adequadamente, sendo difícil falar sobre falta de conhecimento. Ações de curto prazo para preencher lacunas de conhecimento podem funcionar o suficiente para que as mudanças mais significativas pareçam desnecessárias. O know-how em uma PME pode ser facilmente perdido ou fragmentado quando o proprietário vende o negócio ou se aposenta.

Segundo Bukowitz e Williams (2002), as empresas precisam buscar uma forma para atrair e cultivar o conhecimento, que criará valor de longo prazo para a organização, sendo 
este conhecimento proveniente de funcionários ou clientes. Para que as organizações atinjam os objetivos da GC, não basta que elas foquem na transferência interna de conhecimentos, mas que abranjam clientes e concorrentes. Assim, as possibilidades de inovações são ampliadas e gera-se a verdadeira espiral do conhecimento pregada por Nonaka e Takeushi (1997).

A premissa para que qualquer programa de GC tenha sucesso é que haja relação de confiança entre as empresas e os trabalhadores, sendo a empresa transparente e honesta. 0 colaborador precisa entender que o compartilhamento do conhecimento aumenta o seu valor para a empresa e não que o seu emprego está garantido pelo conhecimento que tem. $O$ conhecimento disseminado, ou seja, o conhecimento coletivo, é o maior ativo das empresas. Gestão do Conhecimento é ter as pessoas certas, com as competências certas, no lugar certo (BUKOWITZ; WILLIAMS, 2002).

O conhecimento tenderá a desempenhar um papel mais significativo sempre que a mudança, a inovação e o crescimento estiverem prosseguindo em um campo competitivo e complexo (GUIA EUROPEU, 2004).

Os benefícios estão diretamente relacionados aos resultados financeiros, porque reduz o custo ou melhora o tempo de ciclo. Outro impacto é o incentivo à inovação, motivado pelo capital intelectual (BUKOWITZ; WILLIAMS, 2002).

\subsection{Modelo de diagnóstico proposto pelo Guia Europeu}

O Guia Europeu fornece um exemplo simples e prático para medir como a organização se posiciona em relação aos processos básicos de gestão do conhecimento. Primeiramente são realizadas 7 perguntas gerais relacionadas à organização como um todo e, em seguida, as seções relacionadas às atividades do conhecimento.

O critério utilizado é uma classificação para cada resposta de 1 a 5 (1 = discordo totalmente, 5 = concordo totalmente). O Guia coloca como importante identificar a classificação fortemente negativa e positiva.

As cinco principais atividades de conhecimento propostas pelo Guia Europeu (2004) e que foram utilizadas para a realização do diagnóstico são: Identificação, Criação, Armazenamento, Compartilhamento e Uso.

Para o Guia Europeu (2004), a identificação do conhecimento existente é essencial para apoiar a tomada de decisões. Para incentivar a reutilização do conhecimento existente, este passo de identificação deve ser frequentemente realizado antes da criação de novos conhecimentos. Métodos e ferramentas de apoio para a identificação do conhecimento são: estratégias de busca sistemática, brainstorming, técnicas de mapeamento e feedback (do cliente).

A criação pode ocorrer dentro da pesquisa e desenvolvimento, pelo estabelecimento de grupos de especialistas, as chamadas Comunidades de Prática, pelo recrutamento de especialistas e pela compra de outra empresa. Sempre as pessoas precisam trazer o seu conhecimento explícito e tácito, a fim de criar conhecimentos novos. Contudo, novas soluções e ótimas ideias muitas vezes não são registradas para reutilização ou aprendizado, sendo crítico determinar a melhor maneira de armazenar esse conhecimento (GUIA EUROPEU, 2004).

Segundo o Guia Europeu (2004), armazenar o conhecimento explícito depende de algumas atividades de apoio, como selecionar, organizar ou categorizar, bem como atualizar e eliminar conteúdo antigo. No entanto, para aproveitar o potencial desse conhecimento, o compartilhamento, deve ser realizado. Ferramentas técnicas para armazenamento de conhecimento incluem: bancos de dados de documentos, sistemas de perguntas e respostas, registros de lições aprendidas, entre outros. 
O compartilhamento do conhecimento é conseguido com o uso de métodos e ferramentas que incluem: intranets/portais, bancos de dados de colaboração, comunidades práticas, rodízio de atividades, coaching, seminários e treinamento. No entanto, se não aceitarmos o conhecimento fornecido por nossos colegas, parceiros ou fornecedores, muitas vezes não alcançamos o objetivo final da $\mathrm{GC}$, que é a próxima atividade do conhecimento (GUIA EUROPEU, 2004).

O conhecimento só pode agregar valor quando está sendo usado em uma organização. Existe muito conhecimento subutilizado, então esta atividade é para se certificar de que todo o esforço gasto nas atividades anteriores valeram a pena. Além disso, esta atividade determina as necessidades de conhecimento e deve sempre servir como um ponto de referência para o conhecimento ser criado, armazenado e compartilhado. Ao aplicar o conhecimento, é possível descobrir algumas lacunas existentes, além de adquirir novas experiências que poderiam representar novos conhecimentos para a organização. Portanto, os processos de conhecimento devem continuar com maior identificação e criação, para se tornarem um processo integrado de GC (GUIA EUROPEU, 2004).

Ainda segundo Guia Europeu (2004), dois requisitos importantes devem ser cumpridos para obter melhorias a partir dessas atividades fundamentais do conhecimento: primeiro, as atividades principais devem ser alinhadas ou integradas nos processos organizacionais e tarefas diárias e em segundo lugar, as atividades principais devem ser cuidadosamente equilibradas de acordo com as especificidades de cada processo de negócios e da organização. As soluções de GC não devem focar somente em uma ou duas atividades isoladamente.

\section{METODOLOGIA}

Inicialmente, foi realizada a busca de informações em literaturas específicas, como artigos, dissertações e teses, sendo que durante a análise ficou evidenciada a pouca exploração do assunto na área de pequenas e médias empresas, principalmente no segmento da construção civil.

Foram levantadas algumas metodologias já utilizadas para a realização de diagnóstico de Gestão do Conhecimento, onde se pode perceber que há poucos estudos sobre o assunto voltados para as pequenas e médias empresas. Assim, a decisão pelo uso da metodologia proposta pelo Guia Europeu se deu a partir do resultado da análise bibliométrica, que demonstrou no estudo de publicações por território que a maior parte das publicações sobre GC em pequenas e médias empresas encontra-se na Europa e na Ásia, justificando-se, dessa forma, a escolha do método.

Quanto à classificação do porte dos estabelecimentos, foi adotado o critério do SEBRAE - Serviço Brasileiro de Apoio às Micro e Pequenas Empresas, apresentado no Tabela 1.

Tabela 1 - Classificação das empresas segundo o SEBRAE

\begin{tabular}{ll}
\hline Porte & Número de funcionários \\
\hline Microempresa & Até 19 empregados \\
Pequeno porte & 20 a 99 empregados \\
Médio porte & 100 a 499 empregados \\
Grande porte & 500 ou mais empregados \\
\hline
\end{tabular}

Fonte: SEBRAE (2019)

O primeiro passo da elaboração do questionário, foi a elaboração de questões para caracterização das empresas e respondentes. Na sequência, foi realizada a tradução do 
questionário de diagnóstico de GC proposto pelo Guia Europeu. Após traduzido, o questionário foi adaptado para a melhor aplicação nas empresas construtoras.

O segundo passo foi a aplicação de questionários piloto em 7 empresas, sendo 7 respondentes que representam o grupo da pesquisa (Diretores e Colaboradores). Neste piloto foram testadas as perguntas adaptadas do Guia Europeu, utilizando-se uma escala de respostas de 3 pontos. O objetivo do uso da escala de 3 pontos era se aproximar da escala de respostas propostas pelo método de Bukowitz e Williams (2002), que contempla 3 escalas de resposta. Em função das respostas do questionário piloto, o questionário foi alterado, pois os respondentes não consideraram a escala adequada, pois sentiram falta de outras opções. A escala foi alterada seguindo o critério proposto pelo Guia Europeu de uma escala de 5 pontos, variando de discordo totalmente e concordo totalmente. A definição da escala também levou em consideração estudos que demonstram ser esta a melhor opção de escala. O Guia coloca como importante identificar a classificação fortemente negativa e positiva.

Foi estabelecido como base de dados o Cadastro das Indústrias do Estado do Paraná do ano de 2017, onde para empresas enquadradas entre 20 e 499 funcionários, retornou uma amostra de 102 empresas. Para o cálculo da amostra, foi considerado um nível de confiança de $90 \%$, com margem de erro de $10 \%$ e a população homogênea, considerando-se que a população definida foi baseada em critérios bem definidos, como segmento, local, porte e qualificação das empresas, sendo a maioria das empresas avaliadas, certificadas. A partir dessa definição, foi calculada a amostragem de 31 empresas.

Uma vez definida a base de dados, em meados de 2018, estabeleceu-se um primeiro contato com os possíveis respondentes via telefone, de forma a explicar o objetivo da pesquisa e solicitar o apoio para obtenção das respostas, com o objetivo de aumentar a confiabilidade dos resultados, visto que durante a aplicação de qualquer questionário, o comprometimento do respondente pode impactar no resultado final. Após obtida a concordância do respondente, foi encaminhado o questionário por e-mail, via formulário do Google e planilha em excel. A aplicação do questionário foi feita para dois grupos: Diretores e Colaboradores, com o objetivo de buscar diferentes visões quanto à GC dentro da empresa e por perfil.

\section{ANÁLISE DOS DADOS}

Para um melhor entendimento, conforme definição do Dicionário Michaelis (on-line), aderência é a manifestação de apoio a uma iniciativa ou causa.

Foram consideradas aderentes as respostas na categoria concordo totalmente. Quando houve prevalência de respostas concordo parcialmente e concordo totalmente, foi considerado com tendência à aderência. A mesma linha de raciocínio foi utilizada para a discordância.

Para efeito de comparação com os resultados de Bukowitz e Williams (2002), foi considerada a soma das de respostas concordo parcialmente e concordo totalmente.

Foram coletados 45 questionários, sendo estes referentes a 32 empresas construtoras distintas. Dos 45 questionários, 19 foram respondidos pela Alta Direção (Diretores e/ou proprietário) e 26 respondidos pela equipe de Colaboradores (Engenharia e Qualidade).

Os resultados foram analisados, considerando as seguintes estratificações:

a) Por questão, considerando as respostas da Direção e Colaboradores.

b) Agrupando as respostas por atividade do conhecimento: Identificação, Criação, Armazenamento, Compartilhamento e uso.

c) Pelo grau de aderência ou não aderência das respostas. 


\subsection{Caracterização das empresas}

Conforme respostas da Direção, $78 \%$ das empresas respondentes são empresas certificadas na ISO 9001 e/ou PBQP-H.

O perfil das empresas respondentes, em sua grande maioria (56\%), é de empresas com mais de 20 anos de existência.

Quanto à realização de reuniões para discussão de processos, predominou entre os respondentes que, em geral, há reuniões mensais, sendo que $12 \%$ dos Colaboradores respondeu que nunca ocorrem reuniões, e $16 \%$ da Direção reportou ausência de reuniões. As respostas da Direção e Colaboradores são compatíveis.

Quanto à existência de grupos de estudos sobre assuntos técnicos, 47,4\% da Direção e $36,4 \%$ dos engenheiros responderam que nunca há encontros para estudos técnicos. $47,4 \%$ da Direção e $36,4 \%$ dos Colaboradores responderam que há encontros uma vez por mês.

Quando perguntado sobre indicadores de desempenho que dão suporte às estratégias da empresa, a maioria dos respondentes $(68,4 \%)$ concorda que os indicadores estão formalmente estabelecidos e são monitorados continuamente. Para a Direção, foram considerados indicadores mais importantes: indicadores financeiros, satisfação dos clientes e qualidade.

Para os Colaboradores, foram considerados indicadores mais importantes os relacionados ao custo e prazo e é citado também o pós-obra.

Quando questionados sobre a ocorrência de falhas durante a execução das tarefas costumam se repetir, como por exemplo, quando ocorre um determinado problema de execução em uma obra e volta a ocorrer na mesma obra ou em outra obra da empresa, a maioria $(57,9 \%)$ dos respondentes concorda que, às vezes, falhas ocorrem. Sendo que $15,8 \%$ concordam que falhas ocorrem com frequência e $21,1 \%$ afirmam que raramente elas ocorrem.

A repetição de falhas ocorre em função da falta de ações efetivas para a solução das causas ou pela falta de gestão do conhecimento utilizado para solucionar o problema. Uma vez que a espiral do conhecimento não seja completada (identificar, criar, armazenar, usar e compartilhar), os problemas recorrerão.

Quanto à contratação de consultorias externas, a maioria das respostas indica a predominância da contratação de consultorias externas para suprir as necessidades de conhecimentos. Essa visão é compartilhada entre a Direção e Colaboradores. Isso demonstra que a empresa usa a contratação de consultorias como ferramenta para a criação dos conhecimentos identificados como necessários.

Quanto à participação do cliente no desenvolvimento do produto/serviço, conforme os respondentes, há predominância de respostas afirmando a consulta ao cliente com frequência ou sempre. Atenção deve ser dada à discrepância das respostas por parte da Direção e Colaboradores, visto que a diferença entre os respondentes é de $13,7 \%$, mais favorável para a Direção.

Quanto aos canais de comunicação utilizados nas empresas para divulgação de informações importantes, prevaleceram como respostas nos dois grupos pesquisados, as reuniões e e-mails.

\subsection{Análise por atividade do conhecimento}

Foi avaliado o resultado em relação as cinco atividades da Gestão do Conhecimento de forma a entender, dentro de cada uma das atividades, como foi a distribuição em relação à aderência à GC. 


\subsubsection{Identificação}

Quanto à identificação do conhecimento, há uma distribuição de respostas em todas as categorias, com convergência das respostas dos Colaboradores e Direção (Figura 1).

Figura 1 - Distribuição das respostas das questões relacionadas à identificação do conhecimento

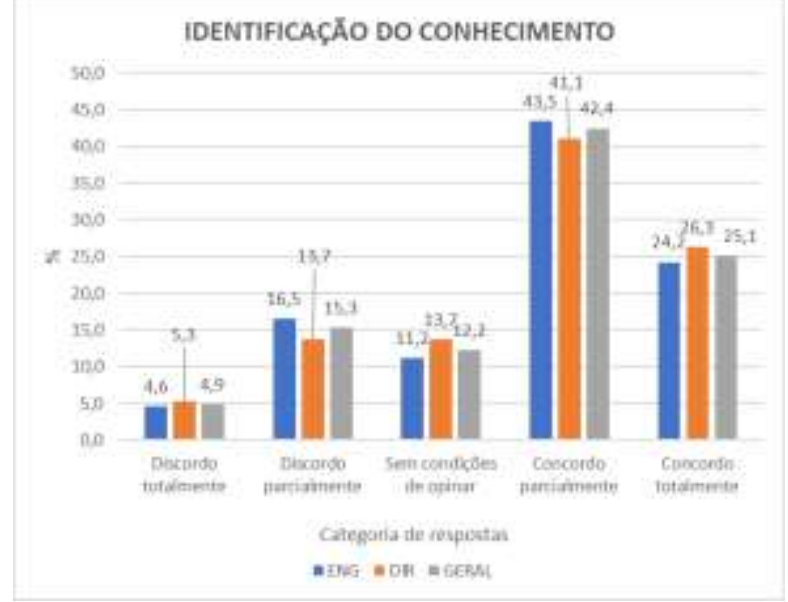

Fonte: Dados da pesquisa (2019)

A soma das respostas discordo totalmente, discordo parcialmente e sem condições de opinar somam $32,4 \%$, sendo superior ao concordo totalmente, mas inferior ao concordo parcialmente, demonstrando uma tendência à aderência.

Na Tabela 2 está apresentado o resumo do resultado da tabulação das respostas do questionário da seção Identificação do Conhecimento.

Tabela 2 - Resumo do resultado da tabulação das respostas do questionário da seção - Identificação (\%)

\begin{tabular}{|c|c|c|c|c|c|c|}
\hline Item & & $\begin{array}{c}\text { Discordo } \\
\text { totalmente }\end{array}$ & $\begin{array}{l}\text { Discordo } \\
\text { parcial- } \\
\text { mente } \\
\end{array}$ & $\begin{array}{c}\text { Sem } \\
\text { condições } \\
\text { de opinar }\end{array}$ & $\begin{array}{l}\text { Concordo } \\
\text { parcialmen- } \\
\text { te }\end{array}$ & $\begin{array}{c}\text { Concordo } \\
\text { totalmen- } \\
\text { te } \\
\end{array}$ \\
\hline \multirow{3}{*}{$\begin{array}{l}\text { A organização sabe qual } \\
\text { conhecimento precisa para dar } \\
\text { suporte a estratégia da empresa. }\end{array}$} & ENG & 3,8 & 11,5 & 7,7 & 50,0 & 26,9 \\
\hline & DIR & 0,0 & 5,3 & 0,0 & 57,9 & 36,8 \\
\hline & TOTAL & 2,2 & 8,9 & 4,4 & 53,3 & 31,1 \\
\hline \multirow{3}{*}{$\begin{array}{l}\text { As pessoas da organização sabem } \\
\text { qual é o conhecimento mais } \\
\text { importante para a empresa. }\end{array}$} & ENG & 3,8 & 11,5 & 15,4 & 50,0 & 19,2 \\
\hline & DIR & 0,0 & 10,5 & 21,1 & 57,9 & 10,5 \\
\hline & TOTAL & 2,2 & 11,1 & 17,8 & 53,3 & 15,6 \\
\hline \multirow{3}{*}{$\begin{array}{l}\text { Se perguntado para diversas pessoas } \\
\text { na empresa, todos dariam a mesma } \\
\text { resposta sobre o qual o conhecimento } \\
\text { mais importante para a empresa. }\end{array}$} & ENG & 11,5 & 23,1 & 11,5 & 50,0 & 3,8 \\
\hline & DIR & 10,5 & 26,3 & 15,8 & 47,4 & 0,0 \\
\hline & TOTAL & 11,1 & 24,4 & 13,3 & 48,9 & 2,2 \\
\hline \multirow{3}{*}{$\begin{array}{l}\text { A organização incentiva os } \\
\text { colaboradores a procurar o } \\
\text { conhecimento existente (internet, } \\
\text { com outras empresas, outros } \\
\text { profissionais, leituras técnicas, etc.) } \\
\text { para evitar perda de tempo }\end{array}$} & ENG & 7,7 & 3,8 & 11,5 & 46,2 & 30,8 \\
\hline & \begin{tabular}{|l|} 
DIR \\
\end{tabular} & 0,0 & 10,5 & 0,0 & 42,1 & 47,4 \\
\hline & TOTAL & 4,4 & 6,7 & 6,7 & 44,4 & 37,8 \\
\hline \multirow{3}{*}{$\begin{array}{l}\text { Na organização, os colegas sabem o } \\
\text { que os outros sabem (um é capaz de } \\
\text { fazer o trabalho do outro). }\end{array}$} & ENG & 11,5 & 26,9 & 11,5 & 50,0 & 0,0 \\
\hline & DIR & 5,3 & 15,8 & 21,1 & 42,1 & 15,8 \\
\hline & TOTAL & 8,9 & 22,2 & 15,6 & 46,7 & 6,7 \\
\hline
\end{tabular}




\begin{tabular}{|c|c|c|c|c|c|c|}
\hline \multirow{3}{*}{$\begin{array}{l}\text { Os colaboradores sabem como } \\
\text { encontrar o conhecimento disponível } \\
\text { (na empresa e fora dela). }\end{array}$} & ENG & 0,0 & 23,1 & 19,2 & 50,0 & 7,7 \\
\hline & DIR & 0,0 & 10,5 & 15,8 & 63,2 & 10,5 \\
\hline & TOTAL & 0,0 & 17,8 & 17,8 & 55,6 & 8,9 \\
\hline \multirow{3}{*}{$\begin{array}{l}\text { A estrutura organizacional da } \\
\text { organização mostra suas áreas de } \\
\text { especialização (o que ela sabe fazer } \\
\text { bem). }\end{array}$} & ENG & 3,8 & 7,7 & 7,7 & 50,0 & 30,8 \\
\hline & \begin{tabular}{|l|} 
DIR \\
\end{tabular} & 0,0 & 15,8 & 21,1 & 26,3 & 36,8 \\
\hline & TOTAL & 2,2 & 11,1 & 13,3 & 40,0 & 33,3 \\
\hline \multirow{3}{*}{$\begin{array}{l}\text { A organização possui sistemas em que } \\
\text { os colaboradores podem facilmente } \\
\text { encontrar o conhecimento disponível } \\
\text { na empresa (intranet, softwares, rede } \\
\text { colaborativa, treinamentos online, } \\
\text { biblioteca, etc.). }\end{array}$} & ENG & 3,8 & 19,2 & 7,7 & 38,5 & 30,8 \\
\hline & DIR & 15,8 & 10,5 & 15,8 & 26,3 & 31,6 \\
\hline & TOTAL & 8,9 & 15,6 & 11,1 & 33,3 & 31,1 \\
\hline \multirow{3}{*}{$\begin{array}{l}\text { A maior parte dos colaboradores } \\
\text { questionam a si mesmos qual o } \\
\text { conhecimento que precisam para } \\
\text { fazer suas tarefas atuais e futuras. }\end{array}$} & ENG & 0,0 & 38,5 & 19,2 & 19,2 & 23,1 \\
\hline & \begin{tabular}{|l|} 
DIR \\
\end{tabular} & 21,1 & 26,3 & 26,3 & 26,3 & 0,0 \\
\hline & TOTAL & 8,9 & 33,3 & 22,2 & 22,2 & 13,3 \\
\hline \multirow{3}{*}{$\begin{array}{l}\text { Tenho consciência do conhecimento } \\
\text { que tenho (o que eu sei) e das minhas } \\
\text { limitações. }\end{array}$} & ENG & 0,0 & 0,0 & 0,0 & 30,8 & 69,2 \\
\hline & DIR & 0,0 & 5,3 & 0,0 & 21,1 & 73,7 \\
\hline & \begin{tabular}{|l|} 
TOTAL \\
\end{tabular} & 0,0 & 2,2 & 0,0 & 26,7 & 71,1 \\
\hline
\end{tabular}

Fonte: Dados da pesquisa (2019)

Quando perguntado se os colaboradores questionam a si mesmos sobre qual o conhecimento que precisam para fazer suas tarefas atuais e futuras, as respostas são inconclusivas, visto que a maior concentração está distribuída no discordo parcialmente $(33,3 \%)$ e o concordo parcialmente $(22,2 \%)$ e que esta questão teve mais respondentes que assinalaram que não tinham condições de opinar (22.2\%). Em discordância total está a visão da Direção e Colaboradores. Enquanto a primeira apresentou $21.1 \%$ dos respondentes na categoria discordo totalmente, a segunda, apresentou $23,1 \%$ no concordo totalmente.

Quando questionado sobre o fato de as pessoas da organização saberem qual é o conhecimento mais importante para a empresa, percebe-se que houve a predominância do concordo parcialmente, com $53,3 \%$. Apenas $15,6 \%$ dos respondentes concordam totalmente, 0 que demonstra que não é claro para as pessoas qual o conhecimento mais importante para a empresa.

As demais questões avaliadas tendem à aderência à $\mathrm{GC}$, sendo as duas afirmações que mais contribuíram para isso foram: A organização incentiva os colaboradores a procurar o conhecimento existente para evitar perda de tempo e tenho consciência do conhecimento que possuo e das minhas limitações, esta última com o maior índice de concordância total.

\subsubsection{Criação}

Quanto à atividade de criação do conhecimento, percebe-se uma tendência à aderência à GC, considerando-se a soma dos concordo parcialmente (40\%) e concordo totalmente $(28,9 \%)$. Fazendo-se a análise da resposta concordo totalmente, a Direção tem uma visão mais positiva, apresentando $33,9 \%$ de concordância total, enquanto os Colaboradores apresentam $25,2 \%$ do mesmo grau de concordância. Considerando o total de respostas, o grau de aderência é de $28,9 \%$, sendo equivalente à atividade de Identificação do conhecimento. $\mathrm{O}$ resultado da análise é apresentado na Figura 2. 
Figura 2 - Distribuição das respostas das questões relacionadas à criação do conhecimento.

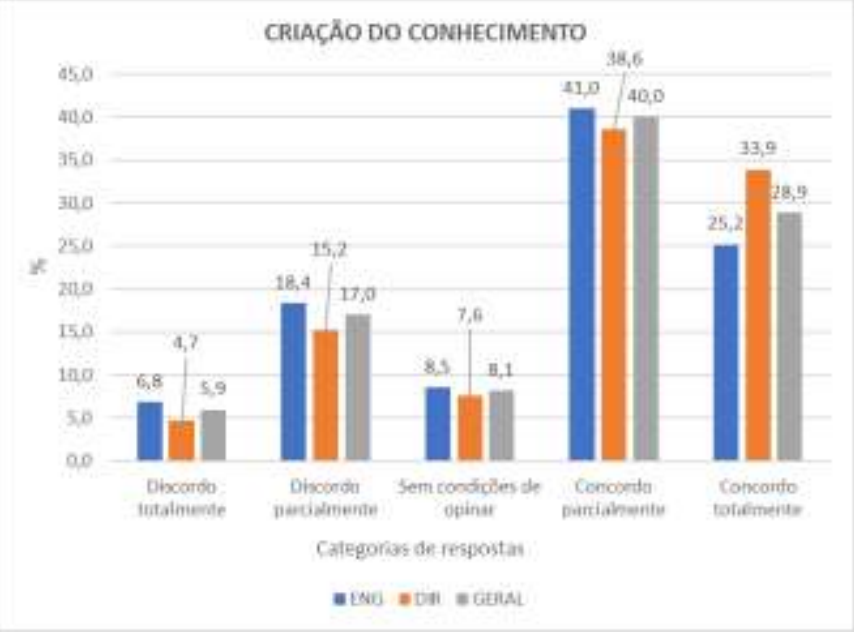

Fonte: Dados da pesquisa (2019)

Na Tabela 3 está apresentado o resumo do resultado da tabulação das respostas do questionário da seção Criação do Conhecimento.

Tabela 3 - Resumo do resultado da tabulação das respostas do questionário - Seção Criação do Conhecimento (\%)

\begin{tabular}{|c|c|c|c|c|c|c|}
\hline Item & & $\begin{array}{l}\text { Discordo } \\
\text { totalmente }\end{array}$ & $\begin{array}{l}\text { Discordo } \\
\text { parcialmente }\end{array}$ & \begin{tabular}{|l|} 
Sem \\
condições \\
de opinar
\end{tabular} & $\begin{array}{l}\text { Concordo } \\
\text { parcialmente }\end{array}$ & $\begin{array}{l}\text { Concordo } \\
\text { totalmente }\end{array}$ \\
\hline \multirow{3}{*}{$\begin{array}{l}\text { Existe estratégia explícita para a } \\
\text { aquisição e desenvolvimento do } \\
\text { conhecimento na empresa } \\
\text { (investimento em pesquisa e } \\
\text { desenvolvimento, parcerias, } \\
\text { contratação de consultorias } \\
\text { especializadas, etc.). }\end{array}$} & ENG & 15,4 & 30,8 & 3,8 & 38,5 & 11,5 \\
\hline & DIR & 10,5 & 26,3 & 0,0 & 31,6 & 31,6 \\
\hline & TOTAL & 13,3 & 28,9 & 2,2 & 35,6 & 20,0 \\
\hline \multirow{3}{*}{$\begin{array}{l}\text { Há concordância nos diversos } \\
\text { níveis da organização sobre } \\
\text { como devem ser obtidos novos } \\
\text { conhecimentos. }\end{array}$} & ENG & 11,5 & 26,9 & 11,5 & 42,3 & 7,7 \\
\hline & DIR & 0,0 & 36,8 & 0,0 & 42,1 & 21,1 \\
\hline & TOTAL & 6,7 & 31,1 & 6,7 & 42,2 & 13,3 \\
\hline \multirow{3}{*}{$\begin{array}{l}\text { Os colaboradores } \\
\text { incentivados a adquirir e/ou } \\
\text { desenvolver } \\
\text { conhecimentos (ex.: tempo } \\
\text { disponível no horário de } \\
\text { trabalho para pesquisas e } \\
\text { atualização, incentivo a cursos e } \\
\text { treinamentos, auxílio financeiro } \\
\text { para estudos de forma geral, } \\
\text { grupos de estudos internos da } \\
\text { empresa entre outros). }\end{array}$} & ENG & 7,7 & 15,4 & 11,5 & 42,3 & 23,1 \\
\hline & DIR & 0,0 & 15,8 & 15,8 & 36,8 & 31,6 \\
\hline & TOTAL & 4,4 & 15,6 & 13,3 & 40,0 & 26,7 \\
\hline \multirow{3}{*}{$\begin{array}{l}\text { A maior parte da equipe está } \\
\text { focada em aprender e explorar } \\
\text { novas formas de trabalhar. }\end{array}$} & ENG & 7,7 & 26,9 & 11,5 & 42,3 & 11,5 \\
\hline & DIR & 10,5 & 10,5 & 15,8 & 42,1 & 21,1 \\
\hline & TOTAL & 8,9 & 20,0 & 13,3 & 42,2 & 15,6 \\
\hline
\end{tabular}




\begin{tabular}{|c|c|c|c|c|c|c|}
\hline \multirow{3}{*}{ Sabemos inovar. } & ENG & 7,7 & 7,7 & 11,5 & 50,0 & 23,1 \\
\hline & DIR & 0,0 & 21,1 & 10,5 & 52,6 & 15,8 \\
\hline & TOTAL & 4,4 & 13,3 & 11,1 & 51,1 & 20,0 \\
\hline \multirow{3}{*}{$\begin{array}{l}\text { Desenvolvemos maneiras de } \\
\text { apoiar a criação de novos } \\
\text { conhecimentos (por exemplo, } \\
\text { através de estudos interno na } \\
\text { empresa, estágios, rotação de } \\
\text { trabalho, supervisão de novos } \\
\text { colaboradores por outros mais } \\
\text { experientes). }\end{array}$} & ENG & 11,5 & 19,2 & 11,5 & 42,3 & 15,4 \\
\hline & DIR & 5,3 & 5,3 & 15,8 & 57,9 & 15,8 \\
\hline & TOTAL & 8,9 & 13,3 & 13,3 & 48,9 & 15,6 \\
\hline \multirow{3}{*}{$\begin{array}{l}\text { Temos os sistemas certos para } \\
\text { capturar e com-partilhar novas } \\
\text { ideias e experiências. (sistemas } \\
\text { de comunicação, intranet, } \\
\text { gravação de treina-mentos, } \\
\text { gravação de experiências } \\
\text { vividas, etc.) }\end{array}$} & ENG & 0,0 & 30,8 & 11,5 & 42,3 & 15,4 \\
\hline & DIR & 15,8 & 21,1 & 10,5 & 42,1 & 10,5 \\
\hline & GERAL & 6,7 & 26,7 & 11,1 & 42,2 & 13,3 \\
\hline \multirow{3}{*}{$\begin{array}{l}\text { Tenho interesse em obter } \\
\text { conhecimentos associados à } \\
\text { minha função. }\end{array}$} & ENG & 0,0 & 3,8 & 3,8 & 23,1 & 69,2 \\
\hline & \begin{tabular}{|l|} 
DIR \\
\end{tabular} & 0,0 & 0,0 & 0,0 & 10,5 & 89,5 \\
\hline & GERAL & 0,0 & 2,2 & 2,2 & 17,8 & 77,8 \\
\hline \multirow{3}{*}{$\begin{array}{lr}\text { Sempre } & \text { desenvolvo } \\
\text { efetivamente } & \text { novos } \\
\text { conhecimentos } & \text { quando preciso } \\
\text { disso. } & \end{array}$} & ENG & 0,0 & 3,8 & 0,0 & 46,2 & 50,0 \\
\hline & \begin{tabular}{|l|} 
DIR \\
\end{tabular} & 0,0 & 0,0 & 0,0 & 31,6 & 68,4 \\
\hline & GERAL & 0,0 & 2,2 & 0,0 & 40,0 & 57,8 \\
\hline
\end{tabular}

Fonte: Dados da pesquisa (2019)

Com relação às questões analisadas, as que mais favoreceram a aderência à GC com predominância do concordo totalmente foram: Tenho interesse em obter conhecimentos associados à minha função $(77,8 \%)$ e sempre desenvolvo efetivamente novos conhecimentos quando preciso $(57,8 \%)$.

A questão que apresentou maior divergência nas respostas foi com relação à existência de uma estratégia explícita para a aquisição e desenvolvimento do conhecimento na empresa, com diferença de $20,1 \%$ entre as duas categorias de respondentes na resposta concordo totalmente, com $31,6 \%$ de respostas da Direção e $11,5 \%$ dos Colaboradores.

E ainda, duas questões foram bem inconclusivas, visto a predominância ser no concordo e discordo parcialmente. Foram elas: Há concordância nos diversos níveis da organização sobre como devem ser obtidos novos conhecimentos e temos os sistemas certos para capturar e compartilhar novas ideias e experiências.

\subsubsection{Armazenamento}

Com relação à atividade de armazenamento do conhecimento, pode-se observar que foram obtidas respostas nas 5 categorias, porém, a resposta discordo totalmente é insignificante, conforme apresentado na figura 3.

Considerando-se as respostas concordo parcialmente e concordo totalmente, pode-se perceber que há uma tendência na resposta concordo parcialmente. Com relação à aderência à GC, $28,9 \%$ dos respondentes afirmaram concordar totalmente. Há divergência nas respostas da Direção e Colaboradores. Quando avaliadas as respostas da Direção, 36,8\% concorda totalmente e $34,5 \%$ concorda parcialmente. Quanto os Colaboradores, $23,1 \%$ concorda totalmente, enquanto $49,1 \%$ concorda parcialmente. 
O armazenamento do conhecimento acompanha o resultado das atividades, identificação e criação do conhecimento.

Figura 3- Distribuição das respostas das questões relacionadas ao armazenamento do conhecimento

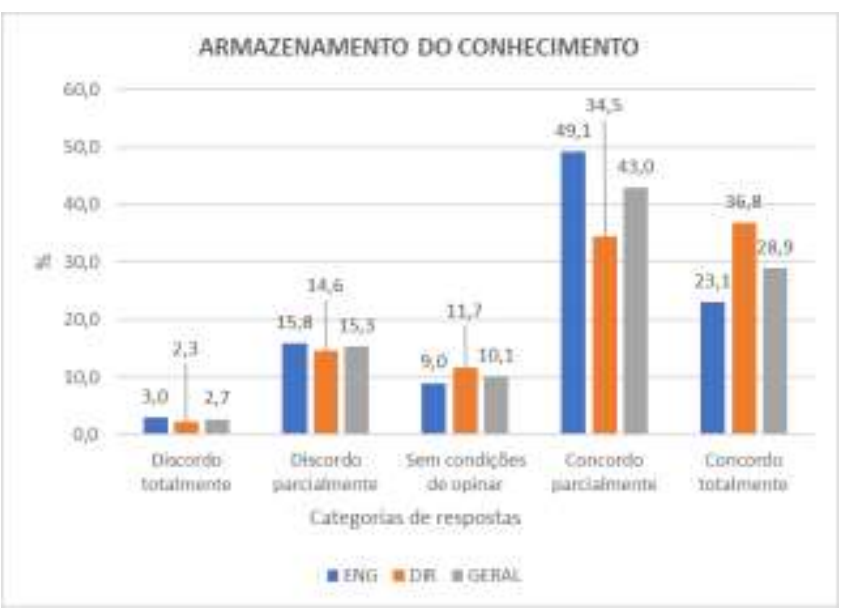

Fonte: Dados da pesquisa (2019)

É apresentado na Tabela 4 o resumo do resultado da tabulação das respostas do questionário da seção Armazenamento do Conhecimento.

Tabela 4 - Resumo do resultado da tabulação das respostas do questionário - Seção Armazenamento

\begin{tabular}{|c|c|c|c|c|c|c|}
\hline Item & & $\begin{array}{l}\text { Discordo } \\
\text { totalmente }\end{array}$ & $\begin{array}{c}\text { Discordo } \\
\text { parcial- } \\
\text { mente }\end{array}$ & $\begin{array}{c}\text { Sem } \\
\text { condições } \\
\text { de opinar }\end{array}$ & $\begin{array}{c}\text { Concordo } \\
\text { parcial- } \\
\text { mente }\end{array}$ & $\begin{array}{c}\text { Concordo } \\
\text { total- } \\
\text { mente }\end{array}$ \\
\hline \multirow{3}{*}{$\begin{array}{l}\text { Temos uma estratégia clara para } \\
\text { armaze-nar nossos ativos de } \\
\text { conhecimento (como captar o } \\
\text { conhecimento de colabo-radores } \\
\text { experientes, jovens colaborado-res } \\
\text { que chegam com novas ideias, etc.) }\end{array}$} & ENG & 11,5 & 26,9 & 7,7 & 42,3 & 11,5 \\
\hline & DIR & 10,5 & 15,8 & 15,8 & 47,4 & 10,5 \\
\hline & GERAL & 11,1 & 22,2 & 11,1 & 44,4 & 11,1 \\
\hline \multirow{3}{*}{$\begin{array}{l}\text { Há concordância nos vários níveis da } \\
\text { organização sobre o conhecimento } \\
\text { que deve ser mantido dentro da } \\
\text { empresa. }\end{array}$} & ENG & 3,8 & 26,9 & 15,4 & 42,3 & 11,5 \\
\hline & DIR & 0,0 & 21,1 & 10,5 & 42,1 & 26,3 \\
\hline & GERAL & 2,2 & 24,4 & 13,3 & 42,2 & 17,8 \\
\hline \multirow{3}{*}{$\begin{array}{l}\text { A Direção/Gerência incentiva o } \\
\text { pessoal a capturar experiências e } \\
\text { lições aprendi-das e fazer com que } \\
\text { estas estejam acessíveis para outros } \\
\text { colaboradores. }\end{array}$} & ENG & 3,8 & 7,7 & 11,5 & 46,2 & 30,8 \\
\hline & DIR & 0,0 & 5,3 & 5,3 & 42,1 & 47,4 \\
\hline & GERAL & 2,2 & 6,7 & 8,9 & 44,4 & 37,8 \\
\hline \multirow{3}{*}{$\begin{array}{l}\text { Os funcionários investem seu tempo } \\
\text { e se esforçam para contribuir com a } \\
\text { base de conhecimento corporativa. }\end{array}$} & ENG & 0,0 & 23,1 & 19,2 & 38,5 & 19,2 \\
\hline & DIR & 5,3 & 21,1 & 21,1 & 36,8 & 15,8 \\
\hline & TOTAL & 2,2 & 22,2 & 20,0 & 37,8 & 17,8 \\
\hline \multirow{3}{*}{$\begin{array}{l}\text { Temos os sistemas certos, como } \\
\text { bancos de dados, intranets, } \\
\text { sistemas informa-tizados, nos quais } \\
\text { podemos armazenar facilmente o } \\
\text { conhecimento. }\end{array}$} & ENG & 0,0 & 7,7 & 3,8 & 61,5 & 26,9 \\
\hline & DIR & 0,0 & 15,8 & 15,8 & 21,1 & 47,4 \\
\hline & TOTAL & 0,0 & 11,1 & 8,9 & 44,4 & 35,6 \\
\hline Sabemos como e onde podemos & ENG & 0,0 & 15,4 & 0,0 & 69,2 & 15,4 \\
\hline
\end{tabular}




\begin{tabular}{|c|c|c|c|c|c|c|}
\hline \multirow{2}{*}{$\begin{array}{l}\text { armaze-nar nosso conhecimento } \\
\text { para que outros possam reutilizá-lo. }\end{array}$} & DIR & 0,0 & 15,8 & 21,1 & 31,6 & 31,6 \\
\hline & GERAL & 0,0 & 15,6 & 8,9 & 53,3 & 22,2 \\
\hline \multirow{3}{*}{$\begin{array}{l}\text { São definidos responsáveis para } \\
\text { questões relacionadas ao } \\
\text { armazenamento do conhecimento } \\
\text { da organização e pela manutenção } \\
\text { do mesmo. }\end{array}$} & ENG & 7,7 & 23,1 & 3,8 & 57,7 & 7,7 \\
\hline & DIR & 5,3 & 31,6 & 5,3 & 26,3 & 31,6 \\
\hline & GERAL & 6,7 & 26,7 & 4,4 & 44,4 & 17,8 \\
\hline \multirow{3}{*}{$\begin{array}{l}\text { Eu gostaria de contribuir com a base } \\
\text { de conhecimento corporativa. }\end{array}$} & ENG & 0,0 & 0,0 & 11,5 & 34,6 & 53,8 \\
\hline & DIR & 0,0 & 0,0 & 0,0 & 31,6 & 68,4 \\
\hline & GERAL & 0,0 & 0,0 & 6,7 & 33,3 & 60,0 \\
\hline \multirow{3}{*}{$\begin{array}{l}\text { Meu conhecimento pessoal é } \\
\text { efetiva-mente acessível para outros. }\end{array}$} & ENG & 0,0 & 11,5 & 7,7 & 50,0 & 30,8 \\
\hline & DIR & 0,0 & 5,3 & 10,5 & 31,6 & 52,6 \\
\hline & GERAL & 0,0 & 8,9 & 8,9 & 42,2 & 40,0 \\
\hline
\end{tabular}

Fonte: Dados da pesquisa (2019)

De todas as questões avaliadas, $44 \%$ delas não tiveram nenhuma resposta na categoria discordo totalmente, sendo que a questão que apresentou maior percentual nesse item foi sobre a existência de uma estratégia clara para o armazenamento do conhecimento $(22,2 \%)$.

As questões que apresentaram mais concordância foram: Eu gostaria de contribuir para a base de conhecimentos corporativa (60\%), Meu conhecimento pessoal é efetivamente acessível para outros (40\%), A Direção incentiva o pessoal a capturar experiências e lições aprendidas e fazer com que estas estejam acessíveis para outros colaboradores $(37,8 \%)$ e Temos os sistemas certos nos quais podemos armazenar facilmente o conhecimento (35,6\%).

\subsubsection{Compartilhamento}

Quanto à atividade de compartilhamento do conhecimento, há uma maior tendência à aderência à GC, principalmente considerando-se a resposta concordo totalmente. Apesar da divergência das respostas dos Colaboradores (40,6\%) e Direção $(56,7 \%)$, em ambos os grupos, o resultado é bem superior às atividades de Identificação, criação e armazenamento do conhecimento. No total, o nível de aderência foi de 47,4\%, conforme apresentado na Figura 4.

Figura 4 - Distribuição das respostas das questões relacionadas ao compartilhamento do conhecimento

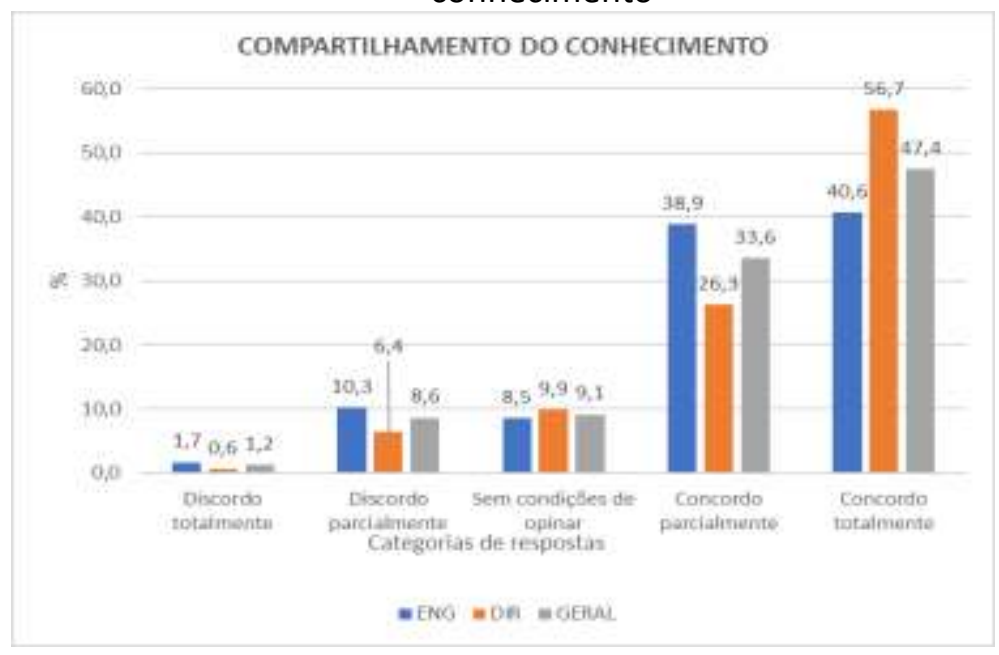

Fonte: Dados da pesquisa (2019) 
A Tabela 5 apresenta o resumo do resultado da tabulação das respostas do questionário da seção Compartilhamento do Conhecimento.

Tabela 5 - Resumo do resultado da tabulação das respostas do questionário - Seção Compartilhamento do Conhecimento (\%)

\begin{tabular}{|c|c|c|c|c|c|c|}
\hline Item & & $\begin{array}{l}\text { Discordo } \\
\text { totalmente }\end{array}$ & $\begin{array}{c}\text { Discordo } \\
\text { parcialmente }\end{array}$ & \begin{tabular}{|c|} 
Sem \\
condições \\
de opinar \\
\end{tabular} & $\begin{array}{c}\text { Concordo } \\
\text { parcialmente }\end{array}$ & $\begin{array}{l}\text { Concordo } \\
\text { totalmente }\end{array}$ \\
\hline \multirow{3}{*}{$\begin{array}{lrr}\text { Para obter sucesso } & \text { na } \\
\text { estratégia da nossa organização } \\
\text { é necessário que } & \text { o } \\
\text { conhecimento } & \text { seja } \\
\text { compartilhado. } & & \end{array}$} & ENG & 0,0 & 3,8 & 0,0 & 34,6 & 61,5 \\
\hline & DIR & 0,0 & 0,0 & 0,0 & 15,8 & 84,2 \\
\hline & TOTAL & 0,0 & 2,2 & 0,0 & 26,7 & 71,1 \\
\hline \multirow{3}{*}{$\begin{array}{l}\text { Na nossa organização, o } \\
\text { "conhecimento compartilhado } \\
=\text { poder" se aplica mais do que } \\
\text { "possuir conhecimento = } \\
\text { poder". }\end{array}$} & ENG & 3,8 & 15,4 & 15,4 & 30,8 & 34,6 \\
\hline & DIR & 0,0 & 10,5 & 21,1 & 15,8 & 52,6 \\
\hline & TOTAL & 2,2 & 13,3 & 17,8 & 24,4 & 42,2 \\
\hline \multirow{3}{*}{$\begin{array}{l}\text { A Direção/Gerência motiva o } \\
\text { pessoal para compartilhar } \\
\text { conhecimento construindo } \\
\text { confiança, dando incentivos, } \\
\text { disponibilizando tempo e } \\
\text { recursos. }\end{array}$} & ENG & 3,8 & 15,4 & 11,5 & 46,2 & 23,1 \\
\hline & DIR & 0,0 & 0,0 & 10,5 & 31,6 & 57,9 \\
\hline & TOTAL & 2,2 & 8,9 & 11,1 & 40,0 & 37,8 \\
\hline \multirow{3}{*}{$\begin{array}{l}\text { Compartilhamos nossas ideias e } \\
\text { experiências com os outros, } \\
\text { mesmo que isso não seja } \\
\text { diretamente relevante para o } \\
\text { nosso trabalho. }\end{array}$} & ENG & 0,0 & 0,0 & 15,4 & 57,7 & 26,9 \\
\hline & DIR & 0,0 & 5,3 & 5,3 & 47,4 & 42,1 \\
\hline & TOTAL & 0,0 & 2,2 & 11,1 & 53,3 & 33,3 \\
\hline \multirow{3}{*}{$\begin{array}{l}\text { Sabemos como otimizar o } \\
\text { compartilhamento dos nossos } \\
\text { conhecimentos uns com os } \\
\text { outros. }\end{array}$} & ENG & 7,7 & 19,2 & 11,5 & 42,3 & 19,2 \\
\hline & DIR & 0,0 & 21,1 & 15,8 & 47,4 & 15,8 \\
\hline & TOTAL & 4,4 & 20,0 & 13,3 & 44,4 & 17,8 \\
\hline \multirow{3}{*}{$\begin{array}{l}\text { A forma como estamos } \\
\text { organizados (departamentos, } \\
\text { setores, estrutura física) não } \\
\text { apresenta barreiras para o } \\
\text { compartilhamento } \\
\text { conhecimento. }\end{array}$} & ENG & 0,0 & 15,4 & 11,5 & 42,3 & 30,8 \\
\hline & DIR & 0,0 & 5,3 & 21,1 & 31,6 & 42,1 \\
\hline & TOTAL & 0,0 & 11,1 & 15,6 & 37,8 & 35,6 \\
\hline \multirow{3}{*}{$\begin{array}{l}\text { Temos os sistemas certos, } \\
\text { como bancos de dados, } \\
\text { intranets, redes internas de } \\
\text { comunicação, e e-mail para } \\
\text { suportar conhecimento } \\
\text { compartilhando. }\end{array}$} & ENG & 0,0 & 7,7 & 7,7 & 50,0 & 34,6 \\
\hline & DIR & 5,3 & 15,8 & 5,3 & 31,6 & 42,1 \\
\hline & TOTAL & 2,2 & 11,1 & 6,7 & 42,2 & 37,8 \\
\hline \multirow{3}{*}{$\begin{array}{l}\text { Eu gosto de compartilhar } \\
\text { minhas ideias e experiências } \\
\text { profissionais com outras } \\
\text { pessoas. }\end{array}$} & ENG & 0,0 & 7,7 & 0,0 & 23,1 & 69,2 \\
\hline & DIR & 0,0 & 0,0 & 5,3 & 10,5 & 84,2 \\
\hline & TOTAL & 0,0 & 4,4 & 2,2 & 17,8 & 75,6 \\
\hline \multirow{3}{*}{$\begin{array}{l}\text { Ao compartilhar meu } \\
\text { conhecimento, faço uma } \\
\text { contribuição significativa para a } \\
\text { organização. }\end{array}$} & ENG & 0,0 & 7,7 & 3,8 & 23,1 & 65,4 \\
\hline & DIR & 0,0 & 0,0 & 5,3 & 5,3 & 89,5 \\
\hline & TOTAL & 0,0 & 4,4 & 4,4 & 15,6 & 75,6 \\
\hline
\end{tabular}

Fonte: Dados da pesquisa (2019) 
Das questões relacionadas ao compartilhamento do conhecimento, $44 \%$ não obtiveram nenhuma resposta no discordo totalmente.

As afirmações que obtiveram maior concordância total foram: Para obter sucesso na estratégia da nossa organização é necessário que o conhecimento seja compartilhado $(71,1 \%)$, Eu gosto de compartilhar minhas ideias e experiências profissionais com outras pessoas $(75,6 \%)$ e Ao compartilhar meu conhecimento, faço uma contribuição significativa para a organização $(75,6 \%)$.

\subsubsection{Uso do Conhecimento}

Analisando-se a última atividade de uso do conhecimento, conforme o Guia Europeu, percebe-se uma tendência à aderência à GC, considerando-se a soma dos concordo parcialmente e concordo totalmente. Avaliando-se a resposta concordo totalmente, há compatibilidade entre o percentual de aderência da Direção $(35,7 \%)$ e Colaboradores $(34,6 \%)$. Considerando o total de respostas, o grau de aderência é de $35,1 \%$, sendo superior à identificação, criação e armazenamento do conhecimento, porém, inferior ao compartilhamento (Figura 5).

Figura 5 - Distribuição das respostas das questões relacionadas ao uso do conhecimento

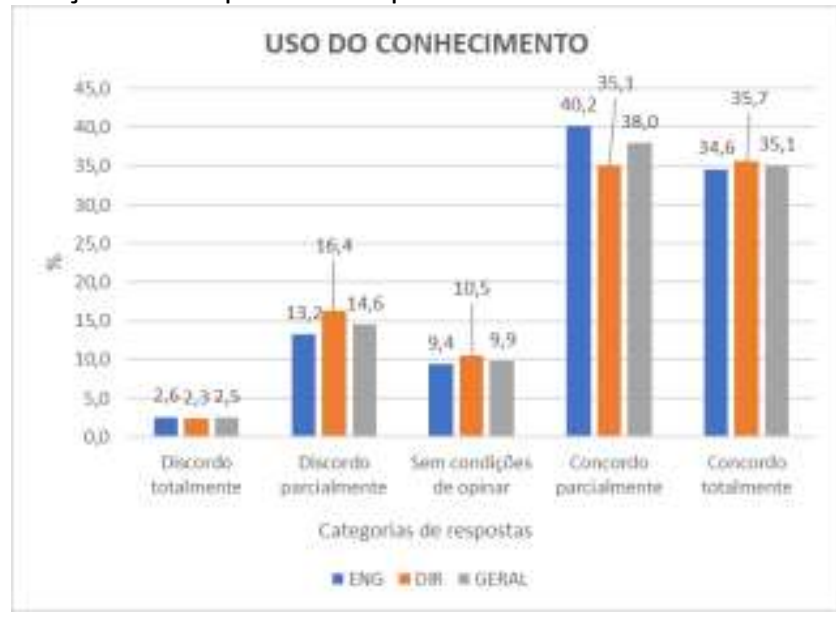

Fonte: Dados da pesquisa (2019)

O resumo do resultado da tabulação das respostas do questionário da seção Uso do Conhecimento está apresentado na Tabela 6.

Tabela 6 - Resumo do resultado da tabulação das respostas do questionário - Seção Uso do Conhecimento (\%)

\begin{tabular}{|c|c|c|c|c|c|c|}
\hline Item & & $\begin{array}{l}\text { Discordo } \\
\text { totalmente }\end{array}$ & $\begin{array}{l}\text { Discordo } \\
\text { parcialmente }\end{array}$ & $\begin{array}{l}\text { Sem } \\
\text { condições } \\
\text { de opinar }\end{array}$ & $\begin{array}{l}\text { Concordo } \\
\text { parcialmente }\end{array}$ & $\begin{array}{l}\text { Concordo } \\
\text { totalmente }\end{array}$ \\
\hline \multirow{3}{*}{$\begin{array}{l}\text { Temos uma abordagem } \\
\text { sistemática para fazer o melhor } \\
\text { uso do conhecimento em } \\
\text { nossos processos de negócios. }\end{array}$} & ENG & 3,8 & 11,5 & 26,9 & 50,0 & 7,7 \\
\hline & DIR & 5,3 & 21,1 & 26,3 & 36,8 & 10,5 \\
\hline & TOTAL & 4,4 & 15,6 & 26,7 & 44,4 & 8,9 \\
\hline \multirow{3}{*}{$\begin{array}{l}\text { Há concordância nos diversos } \\
\text { níveis na organização sobre } \\
\text { como podemos fazer o melhor } \\
\text { uso do nosso conhecimento. }\end{array}$} & ENG & 3,8 & 15,4 & 15,4 & 57,7 & 7,7 \\
\hline & DIR & 0,0 & 42,1 & 5,3 & 36,8 & 15,8 \\
\hline & TOTAL & 2,2 & 26,7 & 11,1 & 48,9 & 11,1 \\
\hline
\end{tabular}




\begin{tabular}{|c|c|c|c|c|c|c|}
\hline \multirow{3}{*}{$\begin{array}{l}\text { Somos encorajados a utilizar o } \\
\text { conhecimento disponível. }\end{array}$} & ENG & 3,8 & 11,5 & 0,0 & 23,1 & 61,5 \\
\hline & DIR & 0,0 & 0,0 & 15,8 & 42,1 & 42,1 \\
\hline & TOTAL & 2,2 & 6,7 & 6,7 & 31,1 & 53,3 \\
\hline \multirow{3}{*}{$\begin{array}{l}\text { Aplicamos novos conhecimento } \\
\text { para melhorar e inovar em } \\
\text { nosso trabalho. }\end{array}$} & ENG & 3,8 & 3,8 & 3,8 & 34,6 & 53,8 \\
\hline & DIR & 0,0 & 5,3 & 0,0 & 42,1 & 52,6 \\
\hline & \begin{tabular}{|l|} 
TOTAL \\
\end{tabular} & 2,2 & 4,4 & 2,2 & 37,8 & 53,3 \\
\hline \multirow{3}{*}{$\begin{array}{l}\text { Sabemos como podemos usar o } \\
\text { conhecimento disponível em } \\
\text { nosso trabalho. }\end{array}$} & ENG & 0,0 & 3,8 & 15,4 & 42,3 & 38,5 \\
\hline & DIR & 0,0 & 5,3 & 0,0 & 63,2 & 31,6 \\
\hline & TOTAL & 0,0 & 4,4 & 8,9 & 51,1 & 35,6 \\
\hline \multirow{3}{*}{$\begin{array}{l}\text { Sabemos como vincular o } \\
\text { conhecimento aos processos e } \\
\text { atividades do negócio da } \\
\text { empresa. }\end{array}$} & ENG & 0,0 & 3,8 & 11,5 & 46,2 & 38,5 \\
\hline & DIR & 0,0 & 10,5 & 10,5 & 42,1 & 36,8 \\
\hline & TOTAL & 0,0 & 6,7 & 11,1 & 44,4 & 37,8 \\
\hline \multirow{3}{*}{$\begin{array}{l}\text { Temos sistemas que facilitam o } \\
\text { uso do conhecimento } \\
\text { disponível. }\end{array}$} & ENG & 0,0 & 3,8 & 7,7 & 50,0 & 38,5 \\
\hline & DIR & 0,0 & 26,3 & 15,8 & 26,3 & 31,6 \\
\hline & TOTAL & 0,0 & 13,3 & 11,1 & 40,0 & 35,6 \\
\hline \multirow{3}{*}{$\begin{array}{l}\text { Sou flexível na aplicação do } \\
\text { conhecimento de outras } \\
\text { pessoas, para se tornar mais } \\
\text { eficiente, eficaz etc. }\end{array}$} & ENG & 0,0 & 3,8 & 0,0 & 34,6 & 61,5 \\
\hline & DIR & 0,0 & 5,3 & 5,3 & 10,5 & 78,9 \\
\hline & TOTAL & 0,0 & 4,4 & 2,2 & 24,4 & 68,9 \\
\hline \multirow{3}{*}{$\begin{array}{l}\text { Prefiro usar ideias e sugestões } \\
\text { de outras pessoas, em vez de } \\
\text { descobrir por mim mesmo. }\end{array}$} & ENG & 7,7 & 61,5 & 3,8 & 23,1 & 3,8 \\
\hline & DIR & 15,8 & 31,6 & 15,8 & 15,8 & 21,1 \\
\hline & TOTAL & 11,1 & 48,9 & 8,9 & 20,0 & 11,1 \\
\hline
\end{tabular}

Fonte: Dados da pesquisa (2019)

As questões mais favoráveis ao uso do conhecimento foram: Aplicamos novos conhecimentos para melhorar e inovar nosso trabalho $(53,3 \%)$, Somos encorajados a utilizar o conhecimento disponível $(53,3 \%)$ e Sou flexível na aplicação do conhecimento de outras pessoas $(68,9 \%)$.

A questão que apresentou maior tendência à discordância foi: Sou flexível na aplicação do conhecimento de outras pessoas.

Nenhuma questão apresentou total tendência à não aderência.

\subsubsection{Compilação dos resultados}

Quando analisada a distribuição de respostas para as 5 atividades da GC, pode-se constar que o compartilhamento é o que apresenta maior aderência (Figura 6).

Esse resultado é consistente com a afirmação de que a cultura da empresa é baseada na confiança, no respeito, na colaboração e no profissionalismo, em que a maioria concorda totalmente com essa afirmação, não gerando barreiras para o compartilhamento. 
Figura 6 - Percentual de aderência à GC considerando as respostas concordo totalmente

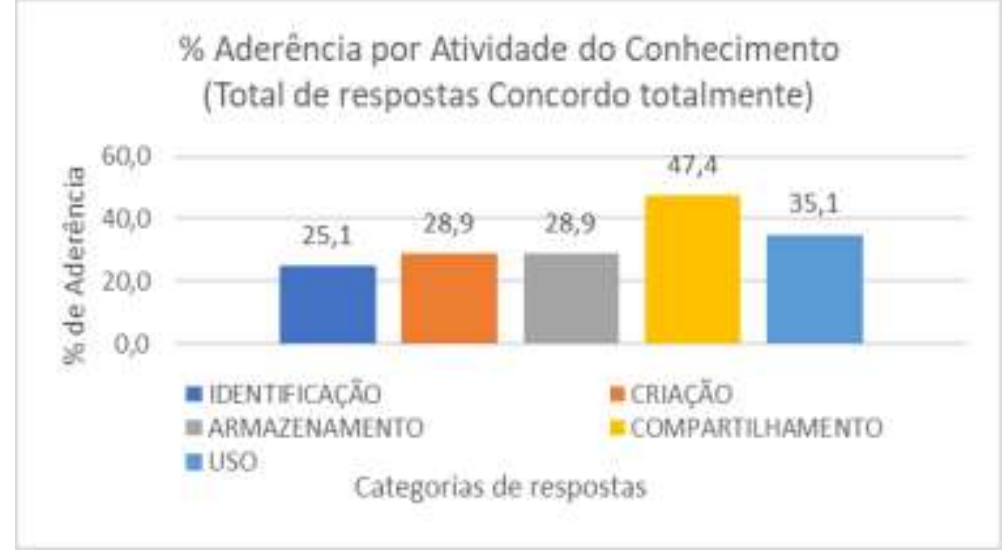

Fonte: Dados da pesquisa (2019)

Quando analisadas as atividades de GC e considerando-se como respostas aderentes à soma das respostas concordo parcialmente com concordo totalmente, pode-se afirmar que o nível médio de aderência é de $72,5 \%$ quando consideradas todas as atividades de GC.

Em todas as atividades do conhecimento pode-se perceber que há uma grande diferença percentual em relação ao nível de aderência e não aderência. Na atividade de identificação do conhecimento, as respostas aderentes são $47,3 \%$ superiores às não aderentes. $\mathrm{Na}$ criação do conhecimento, $45,9 \%$, sendo esta, a menor diferença percentual. No armazenamento, obteve-se $53,8 \%$. No compartilhamento, temos a maior diferença percentual, com $71,1 \%$, e no uso do conhecimento, constatada uma diferença de $56,8 \%$. Na média geral, temos uma diferença de 54,8\%. A Figura 7 apresenta os resultados obtidos.

Figura 7 - Distribuição das respostas das questões relacionadas às 5 atividades da GC, considerando aderente ou não aderente

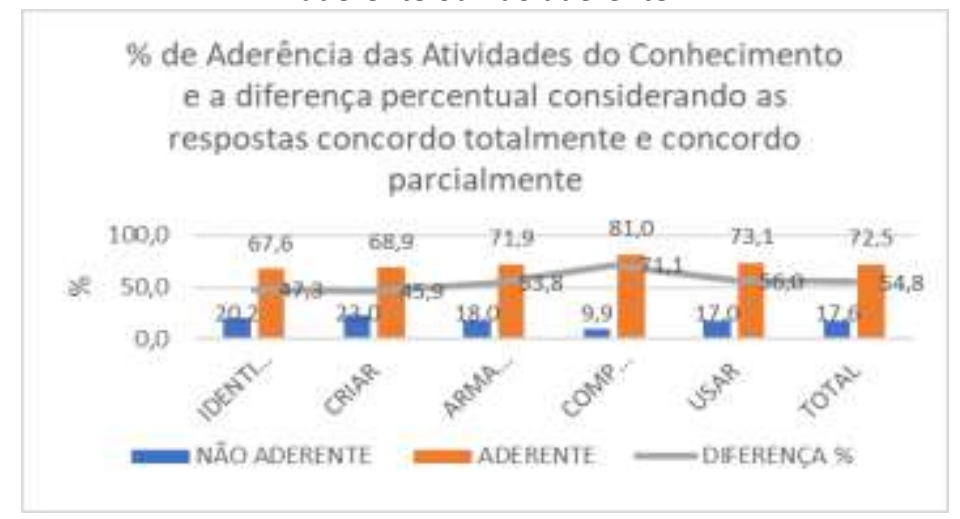

Fonte: Dados da pesquisa (2019)

Quando analisado o panorama geral por categoria de respostas, sem classificação em relação às atividades do conhecimento, pode-se perceber que em todas as respostas houve predominância da categoria concordo parcialmente, com 39,5\%. Em segundo lugar, está a categoria concordo totalmente, que corresponde a $32,9 \%$ dos respondentes, sendo apenas $6,6 \%$ abaixo do concordo parcialmente.

Considerando que a afirmação do discordo totalmente foi apenas de $3,5 \%$ e que o discordo parcialmente foi de 14,2\%, entende-se que sim, há tendência à aderência à GC. Esta categoria de resposta demonstra a aderência às questões relacionadas à GC. O percentual de discordo parcialmente e discordo totalmente não foi significativo. Avaliando-se a categoria de 
respondentes, pode-se afirmar que a Direção tem uma visão mais aderente em relação a dos Colaboradores, sendo 8,2\% superior. Quando analisada a resposta concordo parcialmente, a visão dos Colaboradores é $7,4 \%$ superior a da Direção. $10 \%$ dos respondentes não afirmaram não ter condições de opinar. Mesmo que todos que não souberam opinar, respondessem na categoria discordo totalmente ou discordo parcialmente, ainda assim, o percentual de respostas na categoria concordo totalmente seria superior, o que reforça que há aderência à GC. Os resultados podem ser verificados na Figura 8.

Figura 8 - Panorama geral por categoria de respostas

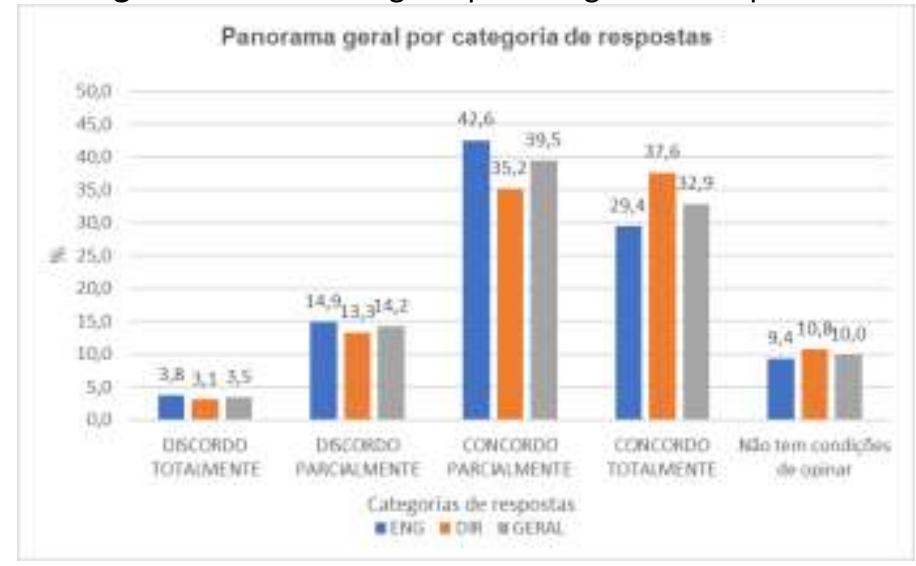

Fonte: Dados da pesquisa (2019)

Quando analisado o percentual de aderência, considerando-se os grupos de categorias aderentes (soma das respostas concordo parcialmente e concordo totalmente) e não aderentes (discordo totalmente e discordo parcialmente) e comparando-se a visão da Direção e Colaboradores, pode-se concluir que há coerência nas respostas, pois tanto na resposta concordo e discordo parcialmente o percentual de respostas são equivalentes (Figura 9).

Figura 9 - Distribuição das respostas das questões relacionadas às atividades da GC, considerando 2 categorias de respostas

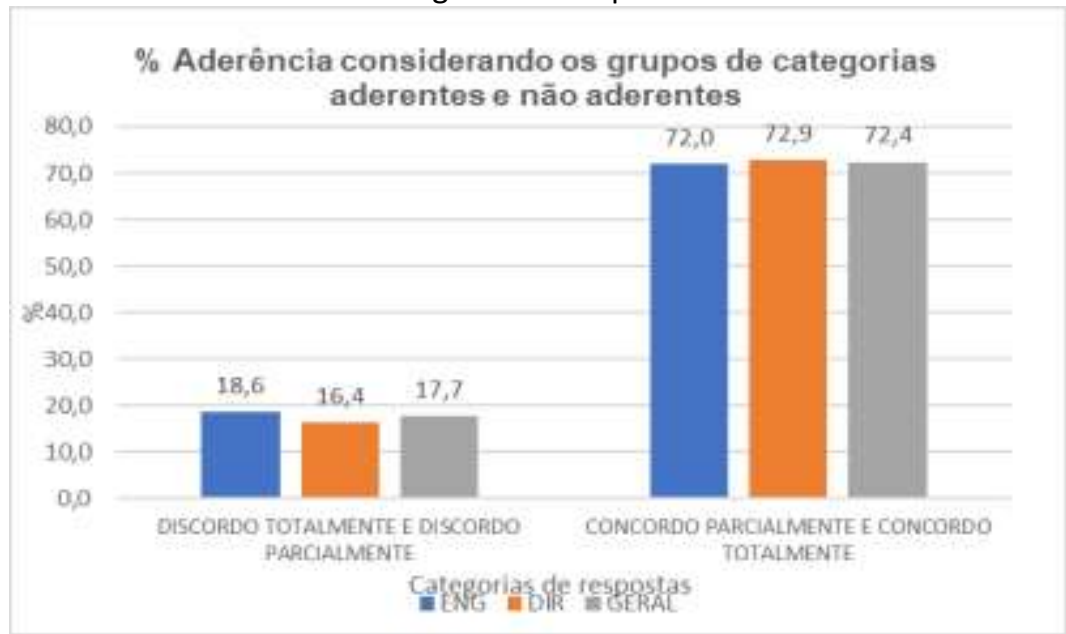

Fonte: Dados da pesquisa (2019)

Quando analisadas apenas as respostas concordo totalmente e discordo totalmente, pode-se perceber claramente a convergência das respostas da Direção e Colaboradores com relação ao discordo totalmente, sendo que o total de respostas corresponde a somente $3,5 \%$ dos respondentes.

Perspectivas em Gestão \& Conhecimento, João Pessoa, v. 10, n. 3, p. 47-74, set./dez. 2020. 
Quando analisada a resposta concordo totalmente, pode-se perceber a convergência das respostas, porém com uma diferença de $8,2 \%$ entre as respostas da Direção e dos Colaboradores, mas totalizando um nível de aderência de 32,9\% de aderência (Figura 10).

Figura 10 - Percentual de aderência considerando-se as respostas concordo totalmente e discordo totalmente

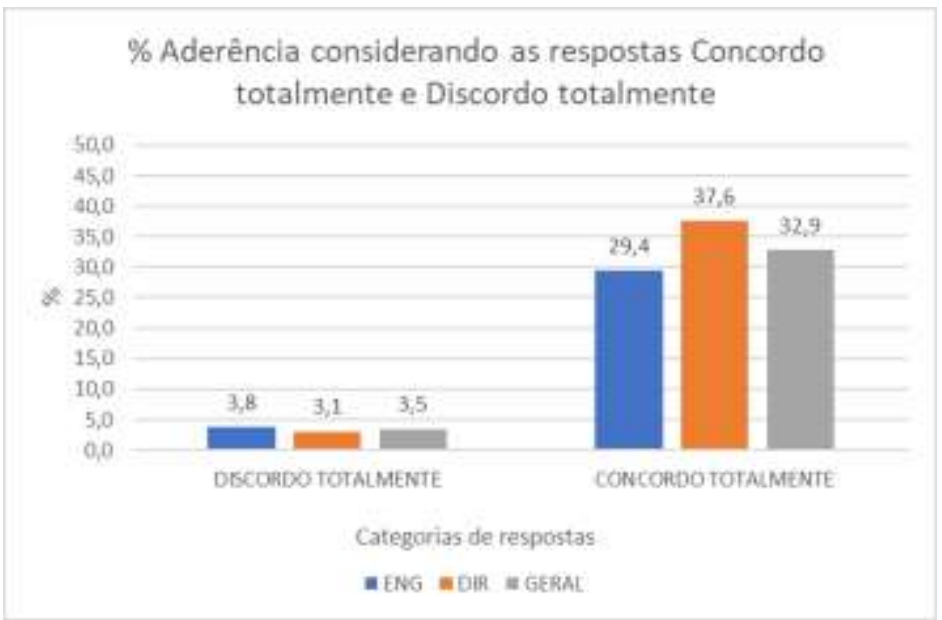

Fonte: Dados da pesquisa (2019)

4.2.7 Comparação de resultados com os diagnósticos realizados pelo Método de Bukowitz e Williams

Durante o processo de levantamento de informações existentes em relação à GC não foi possível identificar resultados de estudos de diagnósticos de GC, baseados no método do Guia Europeu, mas foram identificados alguns estudos nesse sentido, sendo que os mesmos utilizaram o método proposto por Bukowitz e Williams (2002).

Foram compilados dados de 9 estudos realizados em diferentes segmentos, como: ensino, têxtil, papel e celulose, saúde, moveleiro, madeireiro e uma incubadora. No Quadro1 são apresentados os dados compilados.

Quadro 1 - Compilação do resultado de diagnósticos baseados no método de Bukowitz e Williams $(2002)$

\begin{tabular}{|c|c|c|c|c|c|c|c|c|c|}
\hline \multicolumn{6}{|c|}{ Processo Tático } & \multicolumn{4}{|c|}{ Processo estratégico } \\
\hline $\begin{array}{l}\text { Segmento } \\
\text { avaliado }\end{array}$ & Ano & Obtenha & $\begin{array}{l}\text { Utili- } \\
\text { ze }\end{array}$ & Aprenda & $\begin{array}{l}\text { Contri- } \\
\text { bua }\end{array}$ & Avalie & $\begin{array}{c}\text { Construa } \\
\text { Mante- } \\
\text { nha }\end{array}$ & Descarte & Total \\
\hline $\begin{array}{l}\text { SEBRAE-PB } \\
\text { - Ensino }\end{array}$ & $\begin{array}{l}200 \\
9\end{array}$ & 67,63 & 61,49 & 69,39 & 46,75 & 41,32 & 64,56 & 49,21 & 57,19 \\
\hline $\begin{array}{l}\text { Instituição } \\
\text { privada de } \\
\text { Ensino } \\
\text { Superior do } \\
\text { Nordeste } \\
\text { do Brasil }\end{array}$ & $\begin{array}{l}201 \\
4\end{array}$ & 43,62 & 42,93 & 43,63 & 43,47 & 40,40 & 44,85 & 43,30 & 43,17 \\
\hline $\begin{array}{l}\text { Micro e } \\
\text { Pequenas } \\
\text { empresas } \\
\text { do RN. }\end{array}$ & $\begin{array}{l}200 \\
9 \\
\end{array}$ & 74,74 & 78,33 & 76,79 & 75,13 & 59,62 & 80,26 & 53,30 & 73,91 \\
\hline Indústria & 200 & 69,00 & 67,00 & 62,00 & 60,00 & 65,00 & 51,00 & 62,00 & 63,00 \\
\hline
\end{tabular}




\begin{tabular}{|c|c|c|c|c|c|c|c|c|c|}
\hline têxtil - MG & 9 & & & & & & & & \\
\hline $\begin{array}{l}\text { Planta } \\
\text { fabril de } \\
\text { papel-VCP } \\
- \\
\text { Votorantim } \\
\text { Celulose e } \\
\text { Papel. } \\
\text { Especificam } \\
\text { ente a } \\
\text { unidade de } \\
\text { Piracicaba }\end{array}$ & $\begin{array}{l}200 \\
9\end{array}$ & 43,00 & 40,00 & 41,00 & 39,00 & 39,00 & 45,00 & 41,00 & 41,14 \\
\hline $\begin{array}{l}\text { Microempr } \\
\text { esa da área } \\
\text { de saúde } \\
\text { (CLÍNICA } \\
\text { DE } \\
\text { NEFROLOGI } \\
\text { A) do norte } \\
\text { do Estado } \\
\text { do Paraná }\end{array}$ & $\begin{array}{l}201 \\
7\end{array}$ & 65,00 & 70,00 & 68,00 & 58,00 & 60,00 & 51,00 & 58,00 & 61,43 \\
\hline $\begin{array}{l}\text { Indústria } \\
\text { de móveis } \\
\text { em Timbó - } \\
\text { SC }\end{array}$ & $\begin{array}{l}200 \\
9\end{array}$ & 75,37 & 75,74 & 73,33 & 63,52 & 47,22 & 67,59 & 57,96 & 65,82 \\
\hline $\begin{array}{l}\text { DGC em } \\
\text { uma } \\
\text { incubadora } \\
\text { - Avaliação } \\
\text { de } 10 \\
\text { empresas }\end{array}$ & $\begin{array}{l}201 \\
5 \\
\end{array}$ & 77,80 & 80,80 & 80,50 & 80,50 & 64,50 & 78,80 & 79,20 & 77,44 \\
\hline $\begin{array}{l}\text { Indústria } \\
\text { fabricante } \\
\text { de painéis } \\
\text { de madeira } \\
\text { localizada } \\
\text { no estado } \\
\text { do Paraná }\end{array}$ & $\begin{array}{l}200 \\
9 \\
\end{array}$ & 93,33 & 88,33 & 88,33 & 85,00 & 91,67 & 93,33 & 85,00 & 82,29 \\
\hline Média & & 67,72 & 67,18 & 67,00 & 61,26 & 56,53 & 64,04 & 58,77 & 62,82 \\
\hline $\begin{array}{l}\text { Desvio } \\
\text { Padrão }\end{array}$ & & 16,07 & 16,57 & 15,92 & 16,45 & 16,87 & 17,40 & 14,97 & 14,21 \\
\hline
\end{tabular}

Fonte: Dados da pesquisa (2019)

Quando analisados os resultados desta pesquisa em empresas construtoras de pequeno e médio porte da cidade de Curitiba, utilizando-se o método estabelecido no Guia Europeu, considerando as respostas concordo totalmente e concordo parcialmente, obtivemos o resultado apresentado no Quadro 2: 
Quadro 2 - Resultados do diagnóstico realizado em empresas construtoras de pequeno e médio porte de Curitiba

\begin{tabular}{|l|l|l|l|l|l|}
\hline \multicolumn{7}{|c|}{ Atividades do conhecimento } \\
\hline & Identificação & Criação & Armazenamento & Compartilhamento & Uso \\
\hline Total (\%) & 67,6 & 68,9 & 71,9 & 81,9 & 73,1 \\
\hline
\end{tabular}

Fonte: Dados da pesquisa (2019)

Fazendo-se uma análise quanto às diferenças entre os métodos, pode-se constatar que o método proposto por Bukowitz e Williams (2002) separa a gestão do conhecimento em 2 processos, sendo um tático e outro estratégico.

Estes processos foram subdivididos em 4 atividades do conhecimento no processo Tático (Obtenha, Utilize, Aprenda e Contribua) e 3 atividades do conhecimento no processo Estratégico (Avalie, Construa/ Mantenha, Descarte).

Conforme o método de Bukowitz e Williams, o processo tático é ativado por uma oportunidade ou demanda específica imediata, enquanto o processo estratégico é permanente e não é desencadeado por qualquer evento específico. Enquanto o lado tático exige que todos participem e exibam qualidades de liderança, o estratégico é de responsabilidade da liderança designada formalmente pela Direção e tem caráter contínuo.

O Guia Europeu não faz essa distinção. Ele traz 5 atividades do conhecimento distribuídas em (Identificação, Criação, Armazenamento, Compartilhamento e Uso), que são compatíveis com o processo tático do método proposto por Bukowitz e Williams (B\&W). A atividade "obtenha" do método de B\&W abrange as atividades Identificação e Armazenamento do método do Guia Europeu. Dessa forma, foi realizado um estudo comparativo entre os dois métodos, não incluindo o processo estratégico.

Para efeito de comparação, considerando-se que o método proposto por Bukowitz e Williams considerou peso 3 para respostas FORTE, 2 para respostas MODERADO e 1 para respostas FRACO, quanto ao nível de aderência.

Para esta pesquisa foram consideradas 5 categorias de respostas, sendo uma delas o "sem condições de opinar". Duas categorias foram consideradas com tendência à aderência (concordo totalmente e concordo parcialmente) e duas consideradas com tendência à não aderência (discordo totalmente e discordo parcialmente).

Comparando-se os estudos realizados, pode-se observar que praticamente não há distinção nos resultados quando comparadas as atividades de identificação e criação do conhecimento, sendo estas compatíveis, com uma diferença de apenas $2 \%$ entre as respostas. Quando analisada a atividade de compartilhamento do conhecimento, percebe-se uma diferença maior entre os dois métodos, sendo que o nível de aderência com a aplicação do método do Guia Europeu é 19,7\% maior. Na atividade de uso do conhecimento, a diferença é de 5,9\%. A Figura 11 mostra estes resultados. 
Figura 11 - Gráfico comparativo entre os resultados de estudos realizados pelo método proposto no Bukowitz e Williams e Guia Europeu

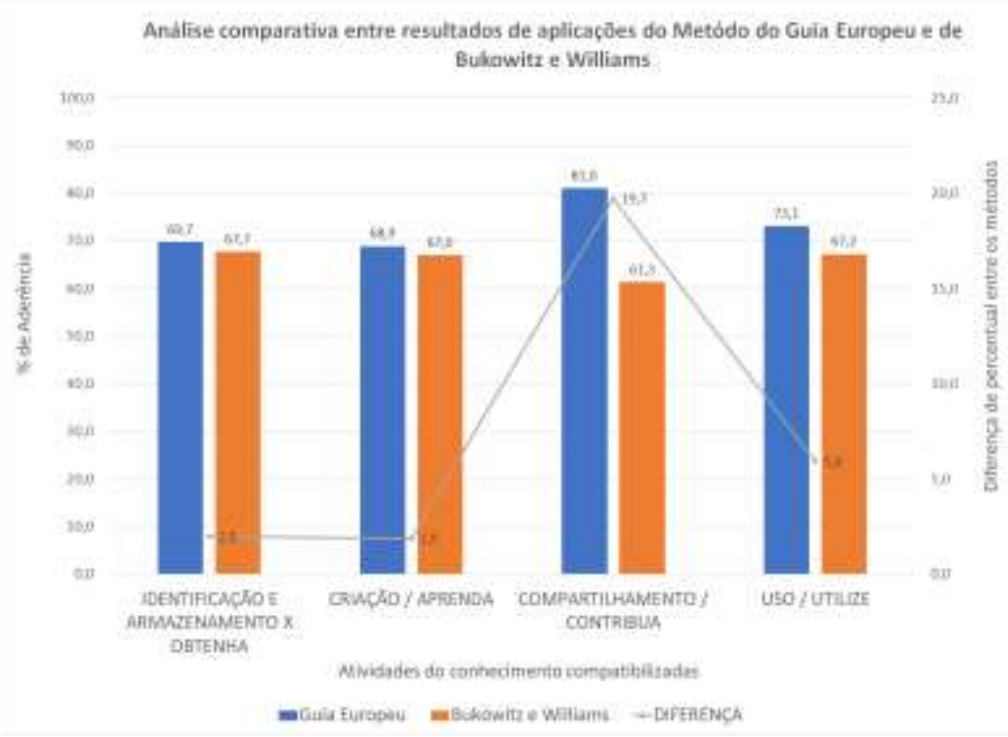

Fonte: Dados da pesquisa (2019)

De qualquer forma, os estudos mostram-se compatíveis no resultado final. Desconsiderando-se o processo Estratégico, e comparando-se apenas o tático, a aderência final dos estudos compilados que utilizaram o método de B\&W foi de $65,8 \%$ e o resultado desta pesquisa, de $72,5 \%$, apresentando uma diferença de aderência de $6,7 \%$.

Se considerado o processo Estratégico, comparando-se os resultados, o método de B\&W foi de $63,2 \%$ e o resultado desta pesquisa de $72,5 \%$, apresentando uma diferença de aderência de 9,3\%. No Quadro 3 são apresentados os resultados obtidos.

Quadro 3 - Resultados da comparação entre os estudos realizados conforme o método proposto por Bukowitz e Williams e pelo Guia Europeu

\begin{tabular}{|l|l|l|l|l|l|l|}
\hline & \multicolumn{3}{|c|}{} & & \\
\hline $\begin{array}{l}\text { Atividades do } \\
\text { conhecimento }\end{array}$ & $\begin{array}{c}\text { Identificação e } \\
\text { Armazenamento/ } \\
\text { Obtenha }\end{array}$ & $\begin{array}{l}\text { Criação / } \\
\text { Aprenda }\end{array}$ & $\begin{array}{c}\text { Compartilhamento } \\
\text { / Contribua }\end{array}$ & $\begin{array}{c}\text { Uso/ } \\
\text { Utilize }\end{array}$ & $\begin{array}{c}\text { Média } \\
\text { Geral }\end{array}$ & $\begin{array}{c}\text { Média } \\
\text { Geral } \\
\text { Incluindo } \\
\text { estratégico }\end{array}$ \\
\hline Guia Europeu & 69,70 & 68,89 & 80,99 & 73,09 & 72,47 & 72,47 \\
\hline $\begin{array}{l}\text { Bukowitz e } \\
\text { Williams }\end{array}$ & 67,72 & 67,00 & 61,26 & 67,18 & 65,79 & 63,21 \\
\hline DIFERENÇA & 1,98 & 1,89 & 19,72 & 5,91 & 6,68 & 9,26 \\
\hline
\end{tabular}

Fonte: Dados da pesquisa (2019)

Segundo Bukowitz e Williams (2002), para cada etapa individual do processo é de 30 a $70 \%$ e a pontuação média de $55 \%$. Assim, pode-se afirmar que os estudos demonstram a aderência à GC, pois todos os resultados apresentaram-se acima do proposto e, ainda, pode-se concluir que, apesar de aparentemente a construção civil ser uma indústria mais atrasada, os resultados equiparam-se a outros segmentos.

\section{CONSIDERAÇÕES FINAIS}

Esta pesquisa teve como objetivo avaliar a gestão das empresas construtoras de pequeno e médio porte de Curitiba quanto ao nível de aderência às práticas de Gestão do 
Conhecimento, por meio da realização de um diagnóstico, conforme modelo proposto no Guia Europeu de Boas Práticas de Gestão do Conhecimento.

Quanto ao objetivo específico, de realizar um diagnóstico de GC nas empresas construtoras de forma a obter informações a respeito das práticas atualmente utilizadas nas empresas, verificou-se que, ao final da aplicação dos questionários e tabulação dos dados, foi possível obter um panorama geral da situação das empresas construtoras em relação à gestão do conhecimento.

Já com relação ao objetivo específico de identificar se há convergência entre a visão da Alta Direção e Colaboradores (Engenheiros/Qualidade) sobre a GC, o resultado demonstrou que a visão é convergente com relação à GC.

E ainda com relação ao objetivo específico que propôs comparar o resultado deste estudo com outros similares realizados por Bukowitz e Williams (2002), o mesmo foi realizado, chegando a um resultado superior ao descrito pelas autoras.

Foram consideradas aderentes as respostas na categoria concordo totalmente. Quando houve prevalência de respostas concordo parcialmente e concordo totalmente, foi considerado que as respostas têm tendência à aderência. A mesma linha de raciocínio foi utilizada para a discordância.

Para efeito de comparação com os resultados de Bukowitz e Williams (2002), foi considerada a soma das respostas concordo parcialmente e concordo totalmente.

Como resultado geral, $33,1 \%$ dos respondentes afirmaram concordar totalmente com as afirmações e $72,4 \%$ afirmaram concordar parcialmente ou totalmente com as afirmações.

Baseado no diagnóstico realizado de acordo com o Guia Europeu, pode-se afirmar que, em comparação ao nível de aderência às práticas de GC realizado por Bukowitz e Williams, se consideradas apenas as respostas concordo totalmente $(31,1 \%)$, o índice está abaixo do proposto pelas autoras, que é de $55 \%$. Já se consideradas as respostas concordo parcialmente e concordo totalmente, o índice é bem superior $(72,4 \%)$. Partindo-se do princípio de que a escala de respostas propostas por Bukovitz e Williams era uma escala de 3 pontos, entende-se que podem ser consideradas a soma do concordo parcialmente e concordo totalmente. Além disso, considerando-se que a margem de erro é de $10 \%$, ainda assim, o resultado estaria superior ao encontrado pelas autoras.

O resultado obtido nesta pesquisa contraria Nunes et al. (2006), que enfatizam que a gestão do conhecimento (GC) é negligenciada pelas PMEs. Foi possível observar que o resultado foi muito favorável, sendo superior inclusive ao resultado de outros segmentos. Considerando-se que $78 \%$ das empresas que participaram da pesquisa são certificadas ISO 9001 e/ou SIAC (PBQP-H), há a percepção de que o resultado positivo pode ter sido influenciado por este fato, sendo necessário um estudo mais aprofundado a respeito, para que seja possível essa afirmação.

Os pontos mais fortes das cinco atividades do conhecimento estão no compartilhamento e uso. A identificação, criação e armazenamento encontram-se no mesmo nível.

Não é possível afirmar o motivo exato do porquê a atividade de compartilhamento do conhecimento se destaca, mas algumas das hipóteses seriam: esta atividade depende em grande parte da vontade do indivíduo e durante a pesquisa foi identificado alto índice de concordância com o fato de a equipe estar altamente motivada a contribuir com os objetivos da organização, bem como pelo fato dos resultados demonstrarem que a cultura das empresas é baseada na confiança, no respeito, na colaboração e no profissionalismo, o que não gera barreiras ao compartilhamento do conhecimento, além da questão de que a maioria das empresas são certificadas, favorecendo a GC, uma vez que há muita informação já documentada. 
A partir dos resultados obtidos, considerando-se os pontos de menor desempenho em cada atividade do conhecimento, recomenda-se às empresas trabalharem melhor algumas questões:

a) Na atividade de identificação do conhecimento, a empresa deve incentivar os colaboradores a se perguntarem qual o conhecimento de que precisam para realização das suas atividades e também informar claramente qual o conhecimento mais importante para a empresa.

b) $\mathrm{Na}$ atividade de criação do conhecimento, deixar claro nos diversos níveis da organização sobre como devem ser obtidos novos conhecimentos e prover sistemas adequados para capturar e compartilhar novas ideias e experiências, bem como informar os colaboradores da existência dos mesmos na empresa.

c) $\mathrm{Na}$ atividade de armazenamento, definir uma estratégia clara para o armazenamento do conhecimento.

d) Na atividade de compartilhamento, há necessidade de orientar a melhor forma de otimizar o compartilhamento dos conhecimentos dentro da empresa.

e) $\mathrm{Na}$ atividade do uso do conhecimento, definir como fazer o melhor uso do conhecimento e reforçar sistemas que facilitem o uso do conhecimento disponível na empresa.

Este estudo apresentou algumas limitações quanto à sua população, amostra e aplicação da pesquisa.

A população definida neste estudo foi baseada somente nos dados do Cadastro das Indústrias do Estado do Paraná do ano de 2017, sendo que não foram consideradas outras fontes em função da dificuldade de obtenção desses dados. Também há o fator limitante em relação à crise econômica que o país vem sofrendo, o que gerou o fechamento de muitas empresas de construção civil neste período.

Outro fator é o tamanho da amostra que foi bastante limitado, pois, apesar do tempo de coleta de respostas ter sido grande, as empresas não retornaram, apesar das diversas tentativas, o que gerou uma margem de erro significativa.

Também não é possível afirmar que houve o correto entendimento das questões por parte dos entrevistados, apesar de ser uma amostra selecionada, considerando-se o nível de gestão da empresa.

A aplicação do questionário foi maioritariamente em empresas certificadas ISO 9001 e/ou SiAC (PBQP-H), o que pode ter influenciado no resultado favorável, visto que uma das consequências de uma certificação é o fato de a empresa possuir uma quantidade maior de informação documentada.

E para finalizar, por esta pesquisa ser uma adaptação do modelo do Guia Europeu e não utilizar exatamente os mesmos critérios de respostas do Modelo de Bukowitz e Williams, as avaliações foram realizadas a partir de premissas estabelecidas neste trabalho, para comparação dos resultados, o que pode não ser um resultado fiel quando aplicado o método prescrito pelas autoras citadas.

\section{REFERÊNCIAS}

ADERÊNCIA. Dicionário on-line Michaelis, 29 maio.2017. Disponível em:http://michaelis.uol.com.br/moderno-portugues/busca/portugues-

brasileiro/ades\%C3\%A3o/. Acesso em: 29 de maio de 2018.

BRITO, Lydia Maria Pinto; BOLSON, Saionara Brano.Gestão do conhecimento: Estudo em uma Instituição Privada de Ensino Superior. Revista RAUnP, v. 6, n. 2, p. 77-87, 2014. Disponível em:

Perspectivas em Gestão \& Conhecimento, João Pessoa, v. 10, n. 3, p. 47-74, set./dez. 2020. 
https://repositorio.unp.br/index.php/raunp/article/view/561. Acesso em: 10 de jan. de 2019.

BUKOWITZ, W. R., WILLIAMS, R. I. Manual de Gestão do Conhecimento. Porto Alegre: Bookman, 2002.

CBIC - Câmara Brasileira da Indústria da Construção. Construção civil - Desafios 2020. 2014. Disponível em: file://C:/Users/Gizele/Downloads/Construcao-Civil-versao-completa.pdf. Acesso em: 29 de abr. de 2018.

CBIC - Câmara Brasileira da Indústria da Construção. Estudo comprova impacto da informalidade na construção civil e norteia ações da CBIC para reduzir sua incidência. 2017. Disponivel em: https://cbic.org.br/estudo-comprova-impacto-da-informalidade-naconstrucao-civil-e-norteia-acoes-da-cbic-para-reduzir-sua-incidencia/. Acesso em: 30 de abr. de 2018.

CBIC - Câmara Brasileira da Indústria da Construção. Análise da Produtividade do Setor de Construção Civil - 2a Versão. 2014. Disponível em:

http://www.cbicdados.com.br/menu/estudos-especificos-da-construcao-civil/produtividadeda-construcao-civil-brasileira. Acesso em: 21 de ago. de 2019.

COSTA, Ivani et al. Diagnóstico de gestão do conhecimento como mecanismo para criação de valor: um estudo exploratório no SEBRAE-PB. Revista Gestão Industrial, v. 05, n. 02: p. 80-98, 2009. DOI: 10.3895/S1808-04482009000200005. Disponível em: https://pt.surveymonkey.com/mp/sample-size-calculator Acesso em: 25 de mar. de 2019.

EUROPEAN COMMITTE FOR STANDARDIZATION. European Guide to good in Knowledge Management. Brussels. 2004.

EZEQUIEL, Karoline Brasil de Oliveira, YAMAGUCHI, Cristina Keiko e WATANABE, Melissa. Redes interorganizacionais e a criação de conhecimento: busca sistemática. Revista Perspectivas em Gestão \& Conhecimento. João Pessoa, v. 9, n. 1, p. 122-137, jan./abr. 2019.

FGV - Fundação Getúlio Vargas. Estudo completo da produtividade da Construção Civil brasileira. 2014. Disponível em: http://www.cbicdados.com.br/menu/estudos-especificos-daconstrucao-civil/produtividade-da-construcao-civil-brasileira. Acesso em: 30 de abr. de 2018.

FIEP - Federação das Indústrias do Estado do Paraná. Cadastro das Indústrias 2017. CD-ROM.

FLORIANO, Jefferson Fabricio; SANTOS, Leomar dos. Aplicação do modelo proposto por Bukowitz e Wiliams no diagnóstico da gestão do conhecimento de uma indústria de móveis em Timbó - SC. In: Encontro Nacional de Engenharia De Produção, 24, 2009, Salvador, BA. Anais. Disponível em: http://www.abepro.org.br/publicacoes/index.asp?pesq=ok\&ano=2009\&area=\&pchave=Aplica \%E7\%E3o+do+modelo+proposto+por+Bukowitz+e+Wiliams+no+diagn\%F3stico+da+gest\%E3o+ do+conhecimento+de+uma+ind\%FAstria+de+m\%F3veis+em+Timb\%F3\&autor=. Acesso em: 10 de jan. de 2019.

FREITAS, E. \& KRAl, L. (2010). Gestão organizacional em empresas familiares no Vale do Rio dos Sinos. REGE Revista De Gestão, 17(4), 387-402. https://doi.org/10.5700/issn.21778736.rege.2010.36715. Acesso em: 12/01/19. 
HOLANDA, I. M. C.; FRANCISCO, A. C.; SCANDOLARA, N. L. Diagnóstico de gestão do conhecimento (dgc): ferramentas e técnicas que criam valor para a empresa. In simpósio de engenharia de produção, 16, 2009, Bauru. Anais.

IBGE - Instituto Brasileiro de Geografia e estatística. SCN - Sistemas de Contas Nacionais, 2015. [online] Disponível em:< https://www.ibge.gov.br/estatisticasnovoportal/economicas/contas-nacionais/9052-sistema-de-contas-nacionais-

brasil.html?edicao=17895\&t=resultados $>$ Acesso em: 22 de jun. de 2018.

KALIL, Mateus Oliveira e LOPES, Sérgio Paulo Maravilha. Perspectivas em gestão e conhecimento: o compartilhamento de informação na construção de uma economia colaborativa e geração de modelos de negócios inovadores. Revista Perspectivas em Gestão \& Conhecimento. João Pessoa. V. 8, n. 3, p. 110-126, set./dez. 2018.

LEONE, Nilda Maria de Clodoaldo Pinto Guerra. As especificidades das pequenas e médias empresas. Revista de Administração, São Paulo V. 34, n. 2, p. 91-94, abril/junho 1999.

MODOLO, Fábio Casagrande. Diagnóstico da Gestão do Conhecimento: um estudo de caso em uma planta fabril de papel. 2005. Dissertação (Mestrado em Engenharia de Produção) Universidade Metodista de Piracicaba, Santa Bárbara D’Oeste, 2005.

NONAKA, I.; TAKEUCHI, H. Criação de conhecimento na empresa. 19. ed. Rio de Janeiro: Elsevier, 1997.

NUNES, M.B., ANNANSINGH, F., EAGLESTONE, B.; WAKEFIELD, R. Knowledge management issues in knowledge-intensive SMEs. Journal of Documentation, v. 62, n. 1, p. 101-119. 2006.

PIRES, Lidiana Antonioli Dal Bem et al. Diagnóstico do nível de gestão do conhecimento em uma microempresa da área da saúde. Revista de Administração Hospitalar e Inovação em Saúde, v.14, n.4, p. 87-102, 2017. DOI: http://dx.doi.org/10.21450/rahis.v14i4.4265. Disponível em: <http://www.spell.org.br/documentos/ver/49656/diagnostico-do-nivel-degestao-do-conhecimento-em-uma-microempresa-da-area-da-saude $>$. Acesso em: 10 de jan. de 2019.

RÉGIS, Josiana Florencia Vieira. A Gestão do conhecimento e a inovação tecnológica como fatores de sobrevivência e de competitividade na sociedade do conhecimento: uma análise exploratória das MPEs do Rio Grande do Norte. 2009. Dissertação (Mestrado em Engenharia de Produção) - Universidade Federal do Rio Grande do Norte, Natal, 2009.

Rotatividade no mercado de trabalho brasileiro: 2002 a 2014. Departamento Intersindical de Estatística e Estudos Socioeconômicos. São Paulo, SP: DIEESE, 2016. Disponível em: https://www.dieese.org.br/livro/2016/rotatividade2016.pdf. Acesso em: 30 de abr. de 2018.

SEBRAE - Serviço Brasileiro de Apoio às Micro e Pequenas Empresas. Reforma da Terceirização e seus impactos na indústria da construção. Boletim de Tendências setembrooutubro/2017.Disponível em: https://sebraeinteligenciasetorial.com.br/produtos/boletins-detendencia/reforma-da-terceirizacao-e-seus-impactos-na-industria-daconstrucao/59ccfbaeb3fff61a0028e212. Acesso em: 22 de jun. de 2018. 
SILVA, Egmar Gonçalves. Diagnóstico das práticas de GC em uma indústria têxtil. 2009. Dissertação (Mestrado Profissional em Administração). Fundação Cultural Dr. Pedro Leopoldo. Pedro Leopoldo, 2009.

Socioeconômicos [responsável pela elaboração da pesquisa, dos textos, tabelas, gráficos e mapas]. Brasília, DF: DIEESE, 2017.528 p. ISSN 1983-2095. Disponível em: https://www.dieese.org.br/anuario/2017/anuarioDosTrabalhadoresPequenosNegocios/?page =1. Acesso em: 31 de mar. de 2019.

TERRA, J. C, Kruglianskas, I. Gestão do conhecimento em pequenas e médias empresas. Rio de Janeiro: Campus, 2003.

TRINDADE, Evelin Priscila et al. Soluções de gestão do conhecimento para pequenas e médias empresas - PMEs. Perspectivas em Gestão \& Conhecimento, v. 6, Número Especial, p. 189203, jan. 2016. ISSN: 2236-417X. Disponível em: http://periodicos.ufpb.br/ojs2/index.php/pgc. Acesso em: 10 de jan. de 2019.

VIANNA, Cleverson Tabajara; GAUTHIER, Fernando Alvaro Ostuni; ANDRADE, Jaine Talita; COSTA Rejane; SCHULTZ, Sérgio Murilo. Bukowitz \& Williams: Diagnóstico de Gestão do Conhecimento em uma Incubadora. In: CONGRESSO INTERNACIONAL DE CONHECIMENTO E INOVAÇÃO, 7., 2017, Foz do Iguaçu, PR. Disponível em: http://proceeding.ciki.ufsc.br/index.php/ciki/article/view/315. Acesso em: 10 de jan. de 2019.

Artigo recebido em 30/08/2020 e aceito para publicação em 21/11/2020 